\title{
1 On the morphology and evolution of cicadomorphan tymbal organs
}

\author{
2 Leonidas-Romanos Davranoglou ${ }^{\mathrm{a}^{*}}$, Beth Mortimer $^{\mathrm{a}}$, Graham K. Taylora, Igor \\ 3 Malenovskýb \\ $4 \quad * e$-mail: lrdreduvius@yahoo.gr \\ 5 aDepartment of Zoology, University of Oxford, Oxford OX1 3PS, U.K. \\ 6 bepartment of Botany and Zoology, Faculty of Science, Masaryk University, Kotlářská 2, Brno, CZ-611 37, \\ 7 Czech Republic
}

8 Abstract. Cicadas and many of their relatives (Hemiptera: Cicadomorpha) generate 9 vibroacoustic signals using tymbal organs located on their first two abdominal segments. 10 Although tymbals are well-studied in Cicadidae, their systematic distribution in other Hemiptera have been debated for more than a century. In the present study, we re-examine the morphology of the musculoskeletal system of cicadomorphan vibroacoustic organs, and we document their systematic distribution in 79 species drawn from across the phylogeny of Cicadomorpha. We also compare their morphology to the recently-described snapping organ of planthoppers (Fulgoromorpha). Based on the structure and innervation of the metathoracic and abdominal musculoskeletal system, we find that several key elements of cicadomorphan vibroacoustic organs that have previously been assigned to the first abdominal segment in fact belong to the second. We find that tymbal organs are nearly ubiquitous in Cicadomorpha, and conclude based on their phylogenetic distribution, that they are likely to be synapomorphic. The unusual tymbal-like organs of the Deltocephalinae and Typhlocybinae, represent derived modifications. Finally, we propose a standardised terminology for sternal components of the cicadomorphan vibrational organs, which can be used in future taxonomic descriptions.

Key words. tymbal, snapping organ, Tymbalia, Auchenorrhyncha, biotremology, bioacoustics.

\section{Introduction}

Cicadas are well-known for their often loud acoustic songs, which have captured the attention of scientists and naturalists since Aristotle first tried to understand their mechanism of sound production (Weiss, 1929). All Cicadas (Cicadoidea, comprising the families Cicadidae and Tettigarctidae) produce their songs using paired buckling structures on the first abdominal tergum, known as tymbals, whose structure was summarized by Young \& Bennet-Clark (1995) as follows: "the tymbal membrane forms a convex dome, which is set in a ring of sclerotised cuticle. Posteriorly on the tymbal, there is an irregularly shaped region of sclerotised cuticle, the tymbal plate, onto which the tymbal muscle attaches dorsally. Anteriorly, there are a number of long sclerotised ribs, which alternate with short ribs arranged in a line. When the tymbal muscle contracts, the tymbal buckles inwards along the line of short ribs in a stepwise manner; each step results in a sound pulse and is due to the buckling of one or more long ribs, beginning with the most posterior". Cicadas are not the only hemipterans to communicate using tymbal organs, however, as many of their cicadomorphan relatives, including the leafhoppers (Cicadellidae), treehoppers (Membracidae), and froghoppers (Cercopoidea) also produce substrate-borne vibrational signals using anatomically similar structures with muscles arranged to pull inward on a distinct area of convex and possibly ribbed or striated cuticle (Ossiannilsson, 1949). Although the anatomical details vary between species, notably in the 
presence or absence of ribs, the buckling dynamics of a tymbal organ are ultimately what define it as such biomechanically.

The morphology, evolution, and biomechanics of the vibroacoustic tymbal organs of cicadas have received considerable attention (e.g. Pringle 1954, 1957; Simmons \& Young, 1978; Young \& Bennet-Clark, 1995; Moulds, 2005; Nahirney et al., 2006; Marshall et al., 2018), but the same cannot be said of the vibrational organs of other cicadomorphans. These have been examined comparatively in only a handful of studies (Ossiannilsson, 1949; Vondráček, 1949; Smith \& Georghiou, 1972; Shaw \& Carlson, 1979; Strübing \& Schwarz-Mittelstaedt, 1986; Miles et al., 2017; Kuhelj et al., 2018), perhaps owing to their small size, the subtlety of their structure, and the fact that they produce songs that are inaudible to the human ear without specialized equipment. Indeed, the systematic distribution of vibroacoustic organs in Cicadomorpha has remained unstudied since the pioneering work of Ossiannilsson (1949). Our limited knowledge of the comparative morphology of tymbal organs contrasts with our extensive knowledge on the systematic distribution of the signals they produce (summarised in Wessel et al, 2014, Appendix Table 1), as their behavioural significance and possible use in pest control has been well investigated (e.g. Cocroft \& McNett, 2006; de Groot et al., 2011; Kuhelj \& Virant Doberlet, 2017; Mazzoni et al., 2017; Takanashi et al., 2019). It also hinders our understanding of the origins of vibroacoustic behaviour in Cicadomorpha, and prevents any formal test of the homology of cicadomorphan tymbals to their counterparts in other Hemiptera.

In light of their complex structure, and the lack of recent comparative studies, even the most fundamental aspects of tymbal organ evolution remain the subject of continuing debate. In particular, a recent review by Wessel et al. (2014) and later commentary by Hoch et al. (2019) conclude that the vibroacoustic organs of all Hemiptera excluding Sternorrhyncha are organs should be called "tymbals", and the clade possessing them the "Tymbalia" (Wessel et al., 2014). We have argued elsewhere that this conclusion is premature (Davranoglou et al., 2019a), and have suggested that the criteria which Wessel et al. (2014) used to define the "tymbalian tymbal organ" require additional morphological information, and a careful reassessment of muscle segmental identity and homology. Such a reappraisal is necessary, because previously authors have variously assigned the sternal components and principal musculature of the tymbal organ to either the first abdominal segment (Ossiannilsson, 1949; Vondráček, 1949), the second abdominal segment (Snodgrass, 1933; Kramer, 1950; Wohlers $\&$ Bacon, 1980), or the flight muscles of the metathorax (Pringle, 1954). Nevertheless, in the 70 years since Ossiannilsson (1949) first assigned most of the tymbal muscles to the first abdominal segment, his conclusions have gone largely unchallenged, and have formed the basis of most subsequent opinion in the study of hemipteran vibroacoustic organs (e.g. Pringle, 1954, 1957; Wessel et al., 2014; Miles et al., 2017; Kuhelj et al., 2018). In summary, the evolution of hemipteran vibroacoustic organs remains a hotly debated topic, with a diversity of theories and interpretations, but until the morphology of cicadomorphan vibroacoustic organs is explored in greater detail across a wider variety of taxa, we can expect little substantive progress in this debate.

In the present study, we analyse the morphology and systematic distribution of cicadomorphan vibroacoustic organs by combining our own new morphological observations with a critical reappraisal of the published literature. Furthermore, we identify similar structures, where 
present, in the vibroacoustic organs of Cicadomorpha and Fulgoromorpha, providing new insight into questions regarding their evolutionary origin. We also update the terminology used for the description of the taxonomically-important sternal sclerites of cicadomorphan vibroacoustic organs, in accordance with our own reinterpretation of their segmental identity.

This new perspective on the morphology and homologies of cicadomorphan vibroacoustic organs aims: (i) to provide the necessary framework for future studies aimed at identifying vibrational organs in Cicadomorpha; (ii) to provide new characters for incorporation into future phylogenetic and taxonomic studies; and (iii) to elucidate the evolutionary origins of vibroacoustic organs more broadly in Hemiptera.

\section{Material and methods}

\subsection{Material}

We described the distribution of tymbal and tymbal-like vibroacoustic organs in 79 species of Cicadomorpha, drawn from 11 of the 12 currently-recognised extant families except Epipygidae (Table 1). We examined material from 67 species deposited in the Natural History Museum, London, UK (BMNH); the Oxford University Museum of Natural History (OUMNH); the Moravian Museum, Brno, Czech Republic (MMBC); the National Museum, Prague, Czech Republic (NMPC); the Paleontological Institute, Russian Aacademy of Sciences, Moscow, Russia (PI); and the Davranoglou Personal Collection (DPC). We also supplemented our sampling of the non-cicadid Cicadomorpha by making use of a small number of earlier literature records for species we could not examine directly (Ossiannilsson, 1949; Vondráček, 1949; Kuhelj et al., 2018). The observational methods, mode of preservation, and depository of each examined species are summarised in Table 1. For most species, we documented the external morphology only. Our description of the corresponding musculature (Table 2) and innervation (Table 3 ) is based on a much narrower sample, which was examined using manual dissections and microtomography, supplemented by earlier observations from the literature (Table 1). In the ethanol-fixed specimens we dissected, the points of insertion of the muscles on the tymbal and tymbal-like organs were preserved, and were consistent with the illustrations of previous authors (e.g. Ossiannilsson, 1949). Our interpretations of the nervous system were mostly based on our dissected Cicadidae, where it was best preserved, and earlier descriptions in the literature (e.g. Vasvary, 1966). The nervous system was only partially preserved in Cercopis (Cercopidae), Lepyronia (Aphrophoridae), Philaenus (Aphrophoridae) and Cicadella (Cicadellidae), but conformed to our interpretation of auchenorrhynchan abdominal segmentation. Finally, to determine the flexibility of the tymbal region, we pulled the tymbal muscle or its apodemes (where present) inwards, using \#5 Dumont forceps.

\subsection{Photomicrography}

Specimens from the different depositories were imaged using the following equipment: 1) a Leica M165c microscope equipped with a Leica DFC490 camera (DPC-OUMNH); a Keyence VHX-5000 digital microscope with VH-Z20T and VH-ZST objectives (MMBC, NMPC); and 3) a Canon EOS 700D camera attached to a Leica MZ125 microscope (BMNH). All resulting stacked images were combined using Helicon Focus (Helicon Soft, Kharkiv, Ukraine) or VHX5000 system software. 
A specimen of an ethanol-preserved Cercopis vulnerata was scanned at the TOMCAT beamline, Swiss Light Source (SLS), Paul Scherrer Institut, Switzerland, at a beam energy of $15.99 \mathrm{keV}$ with final pixel size of $1.625 \mathrm{~mm}$. Three-dimensional reconstruction of the phasecontrasted scans was undertaken using Amira 6.1 software (Mercury Systems).

\subsection{Inference of homology}

We used the three criteria of Patterson (1982) to infer homology between the different exoskeletal and muscular components of the vibroacoustic apparatus: 1) similarity (i.e. homologous structures should display topographic correspondence of the musculature, muscle attachment points, and muscle innervation); 2) conjunction (i.e. two supposed homologues cannot be homologous if they are found together in the same organism); and 3) congruence (i.e. the phylogenetic distribution of a homology should be consistent with the phylogenetic distribution of other homologies). For all of our phylogenetic inferences, we relied on the latest molecular phylogenies of Cicadomorpha (Cryan, 2005; Dietrich et al, 2017; Song et al., 2017; Skinner et al., 2019). We found that most muscles could be readily identified because of their conserved patterns of attachment and innervation, although some were difficult to homologise, especially when the neurological data were absent (see Section 3.7).

\subsection{Terminology}

\subsubsection{Tymbals and tymbal-like organs}

Here, as in our previous works (Davranoglou et al., 2019a, b, c), we use the term "tymbals" in its original functional, morphological, and biomechanical sense. That is, we take the term "tymbal" to describe any hemipteran organ that uses (or is supposed to use) paired areas of buckling cuticle, with or without buckling ribs, in order to generate vibroacoustic signals. We should stress, however, that our inferences are based solely on morphology, such that cuticular buckling to produce vibroacoustic signals is assumed on the basis of their observed structure, or inferred through manipulation. We expressly avoid use of the extended definition of a "tymbalian tymbal" originating from the Tymbalia hypothesis of Wessel et al. (2014), which encompasses the abdominal vibroacoustic organs of all hemipterans excluding the Sternorrhyncha, and which therefore presupposes the homology that the present study provides the necessary basis for testing (see Davranoglou et al., 2019a for further discussion). Our definition of a tymbal organ is useful in being based on the characteristic morphology thereof, which always includes a distinct area of buckling cuticle, typically convex in its relaxed conformation, and often structured with ribs that can be identified even in preserved specimens. Ossiannilsson (1949) used the term "striae" and "striated tymbals" to describe what we describe here as ribbed tymbals, although his terminology is slightly more inclusive, as it includes the barely visible, faint wrinkles on the tymbal or tymbal-like organs of some cicadellids, the biomechanical significance of which is uncertain. In contrast, we use the term "rib" to describe sclerotized, rod-like structures which provide stiffening on the otherwise deformable cuticle of the tymbal.

170 The term "tymbal membrane" itself merits further discussion, because although the area of cuticle between the tymbal ribs is transparent and appears membranous in cicadas, it is actually quite hardened, and is clearly not the same as the soft, flexible membrane surrounding terga 1-2 in most Cicadomorpha. These structural properties make sense biomechanically, because 
the tymbal "membrane" must resist deformation sufficiently to buckle suddenly under muscular load, and because the consequent production of vibrations would not be as efficient in soft cuticle. We maintain use of the term "tymbal membrane" for consistency with previous studies (e.g. Young \& Bennet-Clark, 1995), but stress that it is somewhat imprecise morphologically. Moreover, in non-cicadid Cicadomorpha, there is usually no membranous area as such between their tymbal ribs, if indeed ribs are present at all. Rather, these ribs exist on a recognisably modified area of deformable cuticle, arranged such that it buckles inwards upon contraction of the associated muscles. This modified area of cuticle contrasts with the remainder of tergum 1 , which is stiff and less readily deformable. To identify tymbals in ethanol-preserved and dry mounted specimens, we used some or all of the following characters: 1) presence of a distinct area of ribbed cuticle on tergum 1;2) presence of a distinct area of depigmented cuticle on tergum 1, deformable under manipulation with forceps in ethanolpreserved specimens; 3) presence of distinct attachment points for the principal tymbal muscles; and 4) separation of the tymbal area from the remainder of tergum 1 by a membranous bridge or cuticular elevation.

For species which do not possess readily identifiable buckling or ribbed structures, but which presumably represent modifications of a tymbal bauplan, we use the term "tymbal-like organs".

\subsubsection{Musculature}

Previous studies have used a variety of different terminologies for the musculature of Cicadomorpha, which can make it difficult to confirm which muscle is which across the different species being examined in each study. Here we adopt the terminology of Tröger et al. (2019) for the abdominal musculature, and that of Friedrich \& Beutel (2008) for the metathoracic musculature. Unlike the muscle classification scheme used in our own previous studies of Fulgoromorpha (Davranoglou et al., 2019b, c), these schemes do not classify the dorsoventral muscles as "internal" or "external" based on their position (see e.g. Snodgrass, 1935), which would be difficult to determine consistently across all auchenorrhynchan taxa, because of the exoskeletal transformations of their sterna, and the poorly-understood homologies of their dorsoventral muscles with those of other hemipterans. Based on our homologisation of auchenorrhynchan musculature, we attempt to standardize our terminology with the designations used by previous authors to describe the muscles operating auchenorrhynchan vibroacoustic organs (Table 2), which we do by listing their attachments and innervation (Table 3). We do the same for the different terminologies of the nervous system in Table 4. However, we stress that although our use of the scheme of Tröger et al. (2019) provides a convenient labelling system for auchenorrhynchan muscles, ontogenetic studies will be necessary in order to establish muscle homologies definitively across Hemiptera.

\subsubsection{Abbreviations}

Abbreviations used in the figures: apo: apodeme; apoph: apophysis; bs: basisternum; cl: coxal cleft; cn: connector of terga 1-2; cV: chitinous V; cVa: chitinous V arm; ds: drop-shaped sclerite; dvm: dorsoventral muscle; em: epimeron; es: episternum; fm: folded membrane; fu: furca; gs: gamma-shaped sclerite; ia: internal apodeme of deltocephaline organ; lb: Y-lobe of snapping organ; Ir: long tymbal rib; lt: laterotergite; ma: muscle attachment of stn2a for dvmII1; mb: membrane; ms: metapostnotal sclerite; pl: flap-like plate of tergum 1; pm: proximal margin of tymbal; pocx: postcoxale; prc: process of stn $2 b$; pt: pit of tymbal plate; rb: tymbal rib; rg: ridge; rs: resilin; sa: sternal arm of $\operatorname{stn} 2 b$; scl: sclerite of typhlocybine 
organ; sp: spiracle; sr: short tymbal rib; st, stem of chitinous V; stn: sternum; stn1a: anterior subdivision of sternum 1; stn1b: posterior subdivision of sternum 1; stn2a: anterior subdivision of sternum 2; stn2b: posterior subdivision of sternum 2; tb: tymbal; tc: tymbal cover; td: tendon of tymbal muscle dvmII1; tg: tergum; tm: tymbal membrane; tp: tymbal plate; tr: transverse sclerite of deltocephaline organ; vb: v-bar; vlm: ventral longitudinal muscle; ty: tympanum. Arabic numerals indicate segmental identity of the structure involved.

\section{Results}

In the following sections, we describe the musculoskeletal system and innervation of cicadomorphan vibroacoustic organs, based on sampling of 79 species directly or through wider examination of the available literature (Table 1). We begin by introducing the "classic" tymbal organs of Cicadoidea, whose conformation as reinterpreted here forms the basis of the proceeding comparison with the vibrational organs of Cercopoidea and Membracoidea. Our examination does not aim to be taxonomically exhaustive, but to describe in detail the main components of known tymbal and other abdominal vibrational organs, and their homologies in each cicadomorphan superfamily.

Please note that our interpretation of the segmental identity of auchenorhynchan sternal sclerites and their musculature contrasts with those of most published studies. For this reason, we provide evidence to support our interpretations in our description of the cicadid condition, which is applicable across Auchenorrhyncha, due to the consistent morphology of the relevant parts. Our reinterpretation is explained in more detail in the Discussion (Section 4).

\subsection{Tymbal morphology of Cicada orni Linnaeus, 1758 (Cicadidae: Cicadoidea)}

\subsubsection{Tergal structures}

The following description is based specifically on C. orni, unless explicitly stated otherwise. Tergum 1 is characteristically bipartite: its proximal portion fuses to the metathorax and is membranous (mb; Fig. 1A-C), whereas its distal portion is typically strongly sclerotized ( $\mathrm{t} 1$; Fig. 1A-C) and forms a broad, convex plate. The tymbal organs are paired structures located on either side of the base of tergum 1 (tb; Fig. 1A), and are distinctly separated from the latter by a narrow membrane (white arrows; Fig. 1B, C). Each tymbal possesses long (lr) and short (sr) ribs, which are located on the tymbal membrane (tm; Fig. 1A-C). The proximal margin (pm) of the tymbal consists of a sclerotized U-shaped lobe (Fig. 1B, C). A metapostnotal (?) ridge (rg) fuses to the proximal margin of the tymbal (Fig. 1B, C). The ventral surface of the tymbal is formed by a sclerotized connector [cn; Figs. 1C, 2A-D; Fig. 2D showing the condition in Oligoglena flaveola (Brullé, 1832)] from the second abdominal segment, which incompletely fuses to the tymbal proximal margin (Fig. 2C). This connector is known as the tbar (Young \& Hill, 1977). The distal margin of the tymbal possesses the tymbal plate (tp; Fig. 1B, C), whose distinct pit (pt; Fig. 1B) internally forms the insertion of the main tymbal muscle tendon (td; Fig. 4A). In many species, the tymbal is protected by a flap-like extension of tergum 2 , known as the tymbal cover (partially excised in most figures, complete only in O. flaveola, Fig. 2D).

From the above description, it can be deduced that tymbals are composite organs, consisting of exoskeletal elements pertaining to the metathorax and abdominal segments 1-2.

\subsubsection{Sternal structures}


261 The sterna of the first two abdominal segments are particularly complex, as each is subdivided 262 into two morphologically dissimilar components. The anterior subdivision of sternum 1 (stn1a) is sclerotized and fused to the metathorax on the postcoxale (pocx), and bears the first abdominal spiracle (Figs. 2A-C, 3, red). Internally, two apodemes are present on each side of stn1a: an anterio-median one (apo1; Fig. 3), on which chordotonal organs insert (Young, 1975), and a posterio-lateral one (apo2), which forms the attachment for several muscles (Figs. 2AC, 3; Table 3). Stn1a is succeeded by a folded membrane (fm; Fig. 2A, C), which actually represents the posterior subdivision of sternum 1 ( $\operatorname{stn} 1 \mathrm{~b}$; Fig. 3, blue). The conformation of stn $1 \mathrm{~b}$ as a folded membrane allows the first two segments to fold inwards and outwards upon muscle action, much like an accordion (Pringle, 1954).

Justification for segmental interpretation: Stn1a has been previousy interpreted as the metathorax (Vogel, 1923; Ossiannilsson, 1949). We interpret this as the first abdominal segment which is fused to the metathorax, as: 1) its fusion line to the metathorax is distinctly visible (Figs. 2, 3); 2) it possesses the first abdominal spiracle (Figs. 2, 3); and 3) its muscles (vlmI1, dvmI1-3) receive innervation from the nerve of the first abdominal segment (section 3.1.3.; Table 2).

Sternum 2

The first subdivision of sternum $2(\operatorname{stn} 2 \mathrm{a})$ is represented by a V-shaped structure (in crosssection) known as the chitinous V (after Myers \& Myers, 1928) (cV; Fig. 2B), the base of which is formed by a narrow stem (st; $O$. flaveola, Fig. 2D). The chitinous $\mathrm{V}$ is given its shape by paired, wing-like structures which expand dorsolaterally, known as the chitinous- $\mathrm{V}$ arms (cVa; Figs. 2A-D, including O. flaveola; 3). These arms represent greatly enlarged sternal apodemes which are completely fused to each other, their boundaries being clearly visible in macerated specimens (black dashed line; Fig. 2B). The median, internal portion of each chitinous- $\mathrm{V}$ arm is provided dorsally with a semi-transparent, cup-like chitinous muscle attachment (ma), which forms the origin for the principal tymbal muscle (O. flaveola, Fig. 2D; Fig. 3; Table 3). The chitinous-V arms fuse dorsally with an internal expansion of tergum 2 known as the vertical bar (vb; Fig. 4A, B). The dorsolateral boundary of each chitinous-V arm is fused to a tergal lobe bearing the second abdominal spiracle and the sclerotized connector of the tymbal (O. flaveola, Fig. 2D). In non-cicadid taxa, the muscle attachments forming the main body of the chitinous $\mathrm{V}$ are less strongly fused (if at all), their boundaries being clearly visible (Fig. 4C).

The second subdivision of sternum $2(\operatorname{stn} 2 b)$ is represented by a narrow strip which is fused to sternum 3, its boundaries marked by the antecosta of sternum 3 (Fig. 2A, B, white dashed line). At its extreme lateral margin, stn2b possesses a small apodeme for a dorsoventral muscle (Fig. 2B).

The tympanic organs (ty) are located in the space between stn2a and stn2b (Fig. 3), and are composite structures, formed ventrally by sternum 2 , dorsally by the chitinous $\mathrm{V}$ arms, and laterally by the vertical bar (Fig. 4B). 1954, 1957), while Vogel (1923) considered their adjacent spiracle as the first abdominal one. 
We interpret these structures as part of the anterior sclerite of the second abdominal segment ( $\operatorname{stn} 2 \mathrm{a})$, based on the following characters: 1$)$ the origin of the metathoracic muscle IIIvlm2 marks the anterior border of segment 2 across neopteran insects (Friedrich \& Beutel, 2008). In Auchenorrhyncha, its origin immediately beneath the chitinous $\mathrm{V}$ identifies this structure as part of the second abdominal segment; 2) muscle vlm1 inserts on stn1a and originates beneath the chitinous $\mathrm{V}$, showing that the boundaries of segment 1 are located anterior to the latter structure; 3 ) spiracle 2 is fused to this sclerite; and 4) the tymbal muscle and all other muscles of what we identify as stn2a-b are innvervated by the second abdominal nerve (section 3.1.3.; Table 2)

\subsubsection{Tymbal musculature}

Our proposed homologies of cicadid dorsoventral muscles with those of other Cicadomorpha are summarised in Table 2, whereas their attachments and innervation are provided in Tables 3,4 . In this section, we only mention the musculature associated with cicadid tymbals, which we observed in the male of $C$. orni.

\section{Metathorax:}

IIIvlm2 (Tables 2, 3; Fig. 3): Large and sheet-like muscle, I (=Insertion): metafurca; O (=Origin): median region of antecosta of abdominal sternum $2(\operatorname{stn} 2 a)$, beneath muscle attachments of chitinous V; In. (=Innervation): nerve of first abdominal segment (n. ab. 1; Tables 3, 4; Vasvary, 1966); F (=Function): Contracts the abdomen inwards, towards the metathorax (Pringle, 1954).

\section{First abdominal segment:}

vlmI1 (Tables 2, 3; Fig. 3): Small muscle, beneath IIIvlm2, I: median region of antecosta of abdominal sternum 1 ( $\operatorname{stn} 1 \mathrm{a})$; O: median region of antecosta of $\operatorname{stn} 2 \mathrm{a}$, beneath muscle attachments of chitinous V; In.: n. ab. 1 (Tables 3, 4; Vasvary, 1966); F: Contracts the abdomen inwards, towards the metathorax (Pringle, 1954).

dvmI1 (Tables 2, 3; Fig. 3): Large muscle, I: distal apodeme of stn1a; O: In front of tymbal; In: n. ab. 1 (Tables 3, 4; Vasvary, 1966; Young, 1975; Wohlers et al., 1979; Wohlers \& Bacon, 1980); F: Increases song amplitude by making tymbals more convex (Simmons \& Young, 1978).

Muscles dvmI2-3 (Tables 2, 3), were not observed in this species.

\section{Second abdominal segment:}

vlmII1 (Tables 2, 3; Figs. 3, 4B): small, broad muscle, I: posterior margin of chitinous V base and tympanum; O: antecosta of abdominal sternum 3; In.: nerve of second abdominal segment (n. ab. 2; Tables 3, 4; Vasvary, 1966; Young, 1975; Wohlers et al., 1979); F: Creases the auditory tympanum, protecting it from acoustic damage (Pringle, 1954).

dvmII1 (Tables 2, 3; Figs. 3, 4A, B): Principal tymbal muscle, the biggest abdominal muscle, I: muscle attachment of chitinous $\mathrm{V}$, on stn2a; $\mathrm{O}$ : posterior margin of tymbal, on tymbal plate, via a tendon; In.: n. ab. 2 (Tables 3, 4; Vasvary, 1966; Young, 1975; Wohlers et al., 1979; Wohlers \& Bacon, 1980); polyneuronal innervation known from one species, where this muscle also receives a metathoracic nerve (Table 3; Vasvary, 1966); F: Buckles tymbal (Simmons \& Young, 1978); Comment: Receives trachea of first abdominal spiracle. 
dvmII5 (Tables 2, 3; Fig. 3): Thin, elongate muscle, I: apodeme on stn2b (apo; Figs 2B, 3); O: posterior margin of v-bar; In.: n. ab. 2 (Tables 3, 4; Vasvary, 1966); F: Unknown.

Additional muscles are known from this segment in both sexes of cicadids. Muscle dvmII6 was not observed in this species, but is known from other cicadas (Tables 3, 4; Vasvary, 1966). Tensor tympani muscles 1-3, also not observed here, are of uncertain homology and are usually resorbed in males after molting (Vogel, 1923; Pringle, 1954).

\subsection{Tymbals in Cercopoidea}

Most exoskeletal components of the cicadid tymbal can be found in the tymbals of Cercopoidea. The following description is based on the families Aphrophoridae [species Lepyronia coleoptrata (Linnaeus, 1758) and Neophilaenus campestris (Fallén, 1805)] and Cercopidae (Cercopis vulnerata Rossi, 1807 and Phymatostetha spp.). In the Cercopoidea, tergum 1 is also bipartite: its proximal portion is membranous (mb; Fig. $5 \mathrm{~A}, \mathrm{~B})$, whereas its distal portion is typically sclerotized (t1; Fig. 5A, B). The sclerotized portion of tergum 1 is very narrow, especially medially (Fig. 5A). Tergum 1 is continuous with the tymbals (Fig. 5AE), or is separated from these by a cuticular elevation (in the aphrophorid $N$. campestris, Fig. 6A). Tymbal ribs were observed in all Cercopoidea examined (Figs. 5, 6), and were arranged closely together, with no membrane-like cuticle between them (Figs. 5B, C, 6A-C), in contrast to those of cicadids (Fig. 1A-C). Ribs can be readily visible under an optical microscope (Figs. $5 \mathrm{~A}-\mathrm{C}, 6 \mathrm{~A}-\mathrm{C}$ ), or can be very faint (in C. vulnerata, Fig. 5E), only visible under special

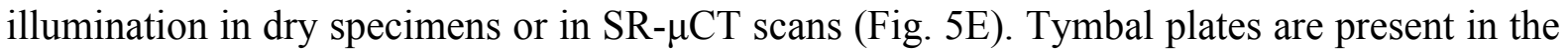
form of flap-like plates (pl; Fig. 5B), but these are not universally present in either cercopids or aphrophorids.

A connector linking terga 1-2 is also present (Figs. 5B, E; 6A), but unlike the condition in the Cicadidae, it is not fused with the second abdominal sternum. A ridge is usually present, fused with tergum 1.

The first two abdominal sterna are similarly subdivided to those of the Cicadidae, although the apodemes for muscle dvmII1 are much smaller and not fused to each other; dvmII1 is usually the largest muscle of the abdomen, and inserts in the posterior margin of the tymbal (Fig. 4D), although other muscles may also be enlarged (e.g. dvmII5; Fig. 4D).

Vibrational signals have been recorded from all families of Cercopoidea (excluding Epipygidae), where up-and-down abdominal motions were observed during signal production (Moore, 1961; Tishechkin, 2003). This led Tishechkin (2003) to suggest that the mechanism was based entirely on abdominal tremulatory movements (i.e. movement of the body relative to the legs), without using any specialised structures such as tymbals. Our observation of distinct tymbals (Figs. 4D; 5; 6), tymbal ribs (Figs. 5B, C, E; 6) and hypertrophied dorsoventral muscles (Fig. 4D) in Cercopoidea contradicts this assumption. Furthermore, as has been shown in treehoppers (Membracidae: Membracoidea), abdominal tremulation is accompanied by clicks (likely tymbal-based, see below), demonstrating that the two mechanisms are not mutually exclusive (Miles et al., 2017).

\subsection{Tymbals in Membracoidea (excluding Deltocephalinae and Typhlocybinae)}

There is considerable diversity in tymbal structure in the Membracoidea, although most of the exoskeletal components are shared with those of other cicadomorphans. Some membracoid 
families such as the Aetalionidae and Membracidae, possess cercopid-like tymbals, which are ribbed and continuous with tergum 1 (Aetalion sp., Fig. 7A; Table 1). We note that although we documented tymbals with distinct ribs in all the membracids we examined (Table 1), Miles et al. (2017) did not find such structures in Umbonia crassicornis (Amyot \& Serville, 1843), but a "rigid apodeme", which we interpret as the tymbal lobe. Other membracoid families such as the Cicadellidae are more variable. For example, the subfamily Cicadellinae contain examples of tymbals lacking obvious ribs (e.g. Proconia sp., Fig. 7C), and separated from tergum 1 by a narrow membrane (white arrow; Fig. 7C). A similar conformation exists in some Ledrinae, although the medial part of tergum 1 is flat and membranous, and the tymbal is continuous with the sclerotized portion of tergum 1 [Ledra mutica (Fabricius, 1803), Fig. 7D]. On the other hand, the condition of certain other Cicadellinae [Cicadella viridis (Linnaeus, 1758)] is unique, with tergum 1 differentiated into distinct lobes (Fig. 7B), which lack distinct tymbal membranes. The lateral lobe possesses faint wrinkle-like structures (dashed lines, Fig. 7B), but these cannot be identified definitively as being homologous to the ribs of other Membracoidea, and due to their small size, it is uncertain whether they are of functional importance. Tergal muscle attachments for dvmII1 are present in a form identical to the cicadid tymbal plate in the Membracidae (present study, not shown; Ossiannilsson, 1949), yet in other families, their structure is similar to the plates found in Cercopoidea, if at all present. A connector linking terga 1-2 is usually present, and as in Cercopoidea, it is not fused to the abdominal sternum (cn; Fig. 7A, B).

In terms of musculature, the same muscles as those of Cercopoidea and Cicadoidea are present in Membracoidea (Tables 2, 3); dvmII1 is frequently the largest abdominal muscle and inserts in distinct sternal apodemes (Fig. 4C), although other muscles may be enlarged and become important or even the principal operators of the vibrational mechanism (Ossiannilsson, 1949; Miles et al., 2017; Kuhelj et al., 2018). At least some Cicadellinae (C. viridis), Eurymelinae [Idiocerus lituratus (Fallén, 1806)] and Deltocephalinae (e.g. certain Opsiini, El-Sonbati, Wilson \& Al-Dhafer, 2018) combine a tymbal-like mechanism with elongated apodemes on stn2a that support an enlarged vlmII1 (Table 1; Fig. 11A; Ossiannilsson, 1949). Some other taxa (e.g. Megophthalminae and Aphrodinae) also possess well-developed apodemes on stn2a but not to the degree with those of the previously mentioned taxa, and their vlmII1 is less voluminous. Vibrational signals have been recorded from the major groups of Membracoidea (e.g. Ossiannilsson, 1949; Appendix Table 1 of Wessel et al., 2014), although the functional morphology of the organs responsible for their production is only known from membracids (Miles et al., 2017). The vibrational organs of the phylogenetically important Myerslopiidae are described separately (in section 3.4. below), as they have remained undocumented to date, and so merit a more extensive account.

\subsection{The tymbals of Myerslopiidae}

Our description provided below is based on the examination of five species of Myerslopiidae (Table 1), and provides the first documentation of the vibrational organs of this family. Although our description cites particular species to link them to the relevant photographs, it is applicable to all the species we have examined, whose pregenital abdominal morphology is very similar.

\subsubsection{Tergal structures}


All pregenital terga are composed of relatively soft cuticle, as they are protected by the mesothoracic wings, which are strongly sclerotized and take the form of tegmina. The proximal portion of tergum 1 has the form of two flap-like sclerites (t1; possibly homologous to the metapostnotal sclerite of Deltocephalinae), whereas most of its median surface is membranous $(\mathrm{mb})$, with a circular sclerite close to its anterior portion [Pemmation bifurca (Knight, 1973); Fig. 8A, black arrow]. Laterally, unribbed tymbals are present in the form of a leaf-like lobe [tb; Fig. 8A in P. bifurca, dashed line; 8B, in P. variabile (Knight, 1973)]. A connector linking tergum 1 to tergum 2 is also present (P. variabile; cn; Fig. B). A ridge was not observed.

\subsubsection{Sternal structures}

Sternum 1 could not be studied due to poor preservation. Sternum 2 is subdivided into a narrow, transparent stn2a, and a broad, strongly sclerotized stn2b [Mapuchea chilensis (Nielson, 1966); Fig. 8C]. Pregenital sterna 3-6 are strongly sclerotized, separated from each other by narrow membranes and are hard to tear apart using forceps in non-macerated specimens.

\subsubsection{Musculature}

Our reconstruction of the myerslopiid musculature is incomplete, due its poor preservation in the specimens examined, although the main muscles operating the tymbal could be observed. Our description is based on M. chilensis.

vlmII1 (Fig. 8D): largest abdominal muscle observed, I: posterior margin of median apodeme of $\operatorname{stn} 2 \mathrm{a}$; O: antecosta of abdominal sternum 3; F: unknown.

dvmII1 (Fig. 8C, D): enlarged dorsoventral muscle (but not to the degree observed in other Cicadomorpha), I: on lateral apodeme of stn2a; O: base of tymbal lobe; F: tymbal buckling (?).

dvmII3 (Fig. 8C, D): short and compact dorsoventral muscle, I: extreme lateral margin of stn2a; O: slightly lower than tymbal base; F: unknown.

dvmII5 (Fig. 8D): long and very thin muscle, I: lateral portion of stn2b; O: antecosta of tergum 2, immediately behind tymbal base; F: unknown.

Overall, the myerslopiid tymbal and its musculature, although somewhat reduced in size, do not depart significantly from the condition found in other Membracoidea. It remains to be determined, however, whether the reduced tymbals of myerslopiids are actually used in vibration production, as efforts to record their songs have so far failed (R. Rakitov \& Y. Tischechkin, personal communication).

\subsection{The vibrational organs of Deltocephalinae}

The vibrational organs of Deltocephalinae are considerably modified compared to other, more generalised Membracoidea. Taxa from the deltocephaline tribes Chiasmini (Doratura), Eupelicini (Eupelix) and Penthimiini (Penthimia) exhibit a simpler condition, described here from D. stylata (Boheman, 1847). In this species, tergum 1 is largely membranous, subdivided into three basic components: 1) a median, drop-shaped sclerite (ds; Fig. 9A); 2) on the main body of tergum 1 (t1; Fig. 9A); and 3) a lateral tymbal-like lobe of tergum 1 (tbl; Fig. 9A, B), whose lower portion bears faint but distinct rib-like structures (white arrows; Fig. 9C; no inference of homology with the ribs of other Cicadomorpha). The ridge is also modified into an elongate metapostnotal sclerite (ms), which terminates close to the drop-shaped sclerite (Fig. 9A). A similar condition can be found in Aphrodes (Ossiannilsson, 1949), where a drop-shaped 
sclerite and a similar rib-bearing lobe is present (Kuhelj et al., 2018), contrary to Ossiannilsson's (1949) statement that "there is no striated tymbal" in this genus. A modified version of the deltocephaline organ can be found in the tribes Athysanini (Euscelis, Macustus), Macrostelini (Macrosteles), Opsiini (Circulifer, Opsius) and Selenocephalini (Selenocephalus). In these taxa, exemplified here by a Selenocephalus sp., the ridge is modified into a Y-shaped sclerite (ms) (Fig. 9D, E), also in close contact with the drop-shaped sclerite (Fig. 9D, E). The main body of tergum 1 is strongly reduced, represented by a transverse sclerite with two spines (tr; Fig. 9E), which is connected posteriorly with a transparent portion of tergum 1. Spiracle 2 is present as a sclerite fused at the base of the tymbal-like lobe (tbl), the latter being modified into possessing gamma-shaped arms (gs) which are in close contact with the Y-shaped sclerite of tergum 1 (Fig. 9E). Tergum 2 is narrow, and its proximal margin possesses two internal apodemes (ia; Fig. 9E). There is no indication of any ribbed structure, although this could have been missed in optical microscopy. However, a SEM examination of a species of Euscelis did not reveal ribs (Strübing \& Schwarz-Mittelstaedt, 1986).

The principal muscles operating the deltocephaline organ are the same as those of cicadomorphan tymbal organs (Table 2), and are found in similar positions (Table 3 ). The largest muscle is dvmII1, originating on the internal apodemes of tergum 2 (white asterisk, Fig. 9D; Ossiannilsson, 1949; Strübing \& Schwarz-Mittelstaedt, 1986). The use of the deltocephaline organ in vibrational communication has been inferred based on the presence of a tymbal-like lobe which bears enlarged dorsoventral muscles, as well as recordings in biotremological studies (Ossiannilsson, 1949; Tishechkin \& Burlak, 2013).

\subsection{The vibrational organs of Typhlocybinae}

The structure of typhlocybine abdominal terga 1-2 is described in Ossiannilsson (1949), who could not observe any of the defining components of tymbal organs in this subfamily. However, Shaw \& Carlson (1979) suggested based on muscle attachments that the tymbal is a thin, unstriated region of the first abdominal tergite lying between a thickened region of this tergite and the thickened antecostal region of the second. Our account differs from that of Ossiannilsson (1949), Vondráček (1949) and Shaw \& Carlson (1979) mainly in the segmental identity of the ventral musculoskeletal components of the typhlocybine abdomen (Fig. 10), which are briefly described below.

\subsubsection{Abdominal apodemes}

The anterior part of the first abdominal sternum ( $\operatorname{stn} 1 \mathrm{a})$ is represented by enlarged triangular apodemes fused to the metathoracic postcoxale (red; Fig. 10), whereas its posterior part (stn1b) is entirely membranous, its boundaries with sternum 2 being undefined. The anterior part of the second abdominal sternum ( $\operatorname{stn} 2 \mathrm{a}$ ) is transverse, provided with a dorsad-facing apophysis, whose proximal margin is less sclerotized and flexible (stn2a apoph; Fig. 10). A small, rounded sclerite of uncertain segmental identity (scl; Fig. 10) is closely associated with stn2a. Stn2b is linked to stn2a by a pair of sternal arms (sa; Fig. 10), and is adjacently provided with a pair of dorsad-facing triangular apophyses ( $\operatorname{stn} 2 b$ apoph; Fig. 10). The posterior margin of $s \operatorname{tn} 2 b$ is greatly expanded posteriorly to form two enormous tongue-like apodemes (apo; Fig. 10), which can extend down to the $6^{\text {th }}$ abdominal segment. The inner proximal margin of each apodeme is modified into an acute process (prc; Fig. 10). 
The size and structure of the apodemes of $\operatorname{stn} 2 \mathrm{~b}$ exhibit considerable interspecific variation, being extremely reduced in some taxa (e.g. Luodianasca, Zygina) (Ossiannilsson, 1981; Qin et al., 2014).

\subsubsection{Musculature}

The musculature operating the typhlocybine vibrational organ is shown in Fig. 10, and the homologies and attachments of the dorsoventral muscles are provided in Tables 2 and 3. Most of the dorsoventral muscles are reduced, whereas the ventral longitudinal muscles of $\operatorname{stn} 2 \mathrm{~b}$ (vlmII1) are greatly enlarged (Fig. 10). The principal tymbal muscle dvmII1 of other cicadomorphans is reduced in typhlocybines and is present only in the females of the examined species (its position marked by a black arrow in Fig. 10; Table 2). The use of the typhlocybine organ as well as the dorsoventral muscles in vibrational communication has been inferred by the enlargement of certain muscles (dvmII4; vlmII1; Fig. 10) and actual recordings of their songs (Shaw, Vargo \& Carlson, 1974; Tishechkin \& Burlak, 2013).

\subsection{Muscle homologies across Cicadomorpha and Fulgoromorpha}

The homologies of auchenorrhynchan abdominal muscles with those recognized and illustrated by previous authors are shown in Table 2 , while their attachments and innervation are provided in Tables 3, 4. Although we based our homologisation on conspicuous similarities in muscle attachment and innervation (Fig. 12; Table 3), comparative studies across different taxa and developmental stages will still be needed to confirm our interpretations.

Homologisation of the ventral longitudinal muscles was fairly straightforward (Table 2), although muscles vlmII2-3 of Typhlocybinae could not be found in any other auchenorrhynchan. The study of dorsoventral muscles was particularly challenging, as they may be poorly preserved, hard to observe, or absorbed in different taxa in the adult stage (e.g. tensor tympani muscles are usually absorbed in male cicadas after their final molt; Pringle, 1957).

We documented a maximum of 3 dorsoventral muscles from stn1a (dvmI1-3), 4 from stn2a (dvmII1-4), and 3 from stn2b (dvmII5-7) (Table 2). Due to their complexity, the homologies of dorsoventral muscles are described in more detail in the sections below, with the terminology of Ossiannilsson (1949) and Davranoglou et al. (2019c) in brackets (O, D, respectively):

\subsubsection{Sternum 1 (stn1a)}

dvmI1 (O: Iadvm3; D: Idvm): In both Cicadomorpha and Fulgoromorpha, it originates on the anterior margin of the base of tergum 1, i.e. the tymbal (Fig. 12A) and the snapping organ Ylobe (Fig. 12B). The muscle Ossiannilsson (1949) termed Iadvm3 in Neophilaenus is not the same with the muscles of the same name found in all other Cicadomorpha he examined (Table 2).

Note: Muscles dvmI2-3 (not shown here) have so far been found only in Cicadidae (Table 2).

\subsubsection{Sternum $2-\operatorname{stn} 2 a$}

dvmII1 (O: Iadvm1; D: IIedvm1): In Cicadomorpha it typically originates on the posterior margin of the tymbal area at the base of tergum 1 (Fig. 12A), while in Fulgoromorpha it originates posteriorly to the anterior margin of the connector (Fig. 12B; Davranoglou et al., 2019c). 
$\boldsymbol{d v m I I 2}$ (O: Iadvm2; D: IIidvm1): In Cicadomorpha it invariably originates on the ridge (Fig. 12A). In Fulgoromorpha, this muscle originates on the membrane in front of the base of tergum 1 (Table 3; Fig. 12B; Davranoglou et al., 2019c).

dvmII3 (O: Iadvm/Iadvm4; D: IIedvm2): It originates at the base of tergum 1 next to the connector in Cicadomorpha (Fig. 12A), while in Fulgoromorpha it originates on the posterior margin of the connector, next to dvmII1 (Fig. 12B).

dvmII4 [O: Iaism; D: IIidvm2 (?)]: It has been found only in the Typhlocybinae in Cicadomorpha, where it originates on the antecosta of tergum 2, above spiracle 2 (Ossiannilsson, 1949; Table 3). A possible homologue of this muscle originates on the posterior margin of tergum 2 of Fulgoromorpha (Fig. 12B; Davranoglou et al., 2019c), although its identity remains ambiguous.

\subsubsection{Sternum $2-\operatorname{stn} 2 b$}

dvmII5 (O: IIadvm; D: -): This is an easily identifiable muscle across Cicadomorpha, invariably found on the posterior margin of tergum 2, close to spiracle 2. This muscle has not been found in any of the Fulgoromorpha examined by Davranoglou et al. (2019c).

dvmII6 (O: IIaism/IIaism2; D: IIisdvm): An intersegmental muscle, which invariably originates at the base of the antecosta of tergum 3, in both Cicadomorpha and Fulgoromorpha (Fig. 12A, B; Table 3; Davranoglou et al., 2019c).

$\boldsymbol{d v m I I 7}$ (O: IIaism1; D: -): Among Cicadomorpha, it has only been found in Typhlocybinae, where it originates on the antecosta of tergum 3, above the origin of dvmII6. A muscle which has been found in all SR $\mu$-CT-examined fulgoromorphan specimens from the dataset of Davranoglou et al. (2019c), but was not described in that study, originates on a similar position, but above the insertion point of dvmII6 (Fig. 12B), is tentatively homologised with the typhlocybine dvmII7. However, the segmental identity of this muscle is ambiguous, as it inserts on the membrane separating stn2b from sternum 3 (Fig. 12B).

Note: In the Cicadidae, dorsoventral muscles other than dvmI1, dvmII1 and dvmII5 are difficult to homologise with those of other Cicadomorpha, due to the extreme expansion of the chitinous V (Fig. 2B; Fig. 3), which has drastically altered the structure and attachment sites of stn2a (Fig. 3). As a result, the tensor tympani muscles of cicadas are of uncertain homology, and were not mentioned in the above list. Tensors tympani 2-3 are present only in females, while tensor tympani 1 is present in both sexes (Vogel, 1923; Wohlers \& Bacon, 1980). Based on their innervation, tensor tympani 3 is considered to represent the highly reduced dvmIII of the females (Wohlers \& Bacon, 1980), whereas tensor tympani 2-3 could be homologous with any of dvmII2-4.

\subsection{Phylogenetic distribution of vibroacoustic organs in the Cicadomorpha}

We show that tymbals can be found in all major branches of Cicadomorpha (Fig. 11). We find that certain taxa in otherwise "tymbaled" clades possess modifications of the morphology of the first two abdominal segments possibly associated with other vibrational mechanisms, such as the small tergal sclerites in Deltocephalinae and the abdominal apodemes of Typhlocybinae (Fig. 11A). Some taxa (e.g. C. viridis) combine greatly enlarged abdominal apodemes with a tymbal-like mechanism (Fig. 11A; Table 1). 
Given the latest phylogenies, the ubiquitous distribution of tymbals and tymbal-like organs in the main clades of Cicadomorpha (Cicadoidea, Cercopoidea, Myerslopiidae and remainder of Membracoidea) suggests that tymbals must have been present at the root of the infraorder (Fig. 11A). If this hypothesis is correct, then the deltocephaline and typhlocybine organs represent secondary developments (i.e. autapomorphies). A further consequence is that the enlarged abdominal apodemes of some Cicadellinae and Deltocephalinae (Fig. 11A) evolved independently from the Typhlocybinae, as they are present in only a subset of the taxa in these subfamilies (Table 1). It should also be noted that the Eurymelinae (= Idiocerinae), which were placed as the sister-group to Typhlocybinae in the recent molecular phylogeny by Dietrich et al., 2017, also possess relatively well-developed apodemes (see Ossiannilsson 1949, 1981).

\section{Discussion}

\subsection{Segmental reinterpretation of auchenorrhynchan vibroacoustic organs}

The fusion of the first abdominal sternum to the metathorax, and the subdivision of sterna 1 and 2 into distinct subunits ( $\operatorname{stn} 1 a, \operatorname{stn} 1 b, \operatorname{stn} 2 a, \operatorname{stn} 2 b$ ), have been the source of considerable confusion for the determination of the segmental identities of the tymbal organ: Vogel (1923) ignored stn1a, which he considered to be a part of the metathorax, and misidentified the chitinous-V (stn2a) and spiracle 2 as the first abdominal segment and spiracle respectively, $\operatorname{stn} 2 \mathrm{~b}$ as the second abdominal segment, and spiracle 3 as spiracle 2. Ossiannilsson (1949) and Vondráček (1949) considered IIIvlm2 and vlmI1 as metathoracic muscles and interpreted their insertion (antecosta 2) as the base of sternum 1, when we show here that the latter in fact represents stn2a. As a result, all muscles present on stn2a, including the primary tymbal muscle dvmII1, were interpreted as pertaining to the first abdominal segment (Table 2). This interpretation was adopted and reproduced by the overwhelming majority of subsequent studies (e.g. Pringle, 1957; Wessel et al, 2014; Miles et al., 2017; Kuhelj et al., 2018). Pringle (1954) suggested that the tymbal muscles and the chitinous $\mathrm{V}$ represented a posteriorly transposed portion of the metathorax, although he later reappraised this theory and adopted the interpretation of Ossiannilsson (1949).

In this study, following a detailed examination of the exoskeleton, musculature and innervation, we have provided a large body of evidence for a re-evaluation of the segmental affinities of cicadomorphan vibroacoustic organs. We have shown that cicadomorphan sterna 1-2 are subdivided, their anterior-most components ( $\operatorname{stn} 1 \mathrm{a}, \operatorname{stn} 2 \mathrm{a})$ receiving the spiracle corresponding to their ascribed segmental identity (spiracles 1 and 2, respectively). Furthermore, our segmental interpretations are supported by the innervation of the muscles and sensory organs: nerves of the first abdominal segment (n. ab. 1) supply the muscles (Table 3) and chordotonal organs (Pringle, 1954; Young, 1975) of stnla, and the second abdominal nerve (n. ab. 2) supplies its corresponding segment as well (Table 3 ). The nerves can be reliably identified as belonging to segments $1-2$, as their sensory fibres are arranged in the mesothoracic ganglion in a way that reflects their metameric organization, i.e. they lie in the neuromere of the segment they innervate (Wohlers et al., 1979; Wohlers \& Bacon, 1980). Pringle (1954) stated that dvmII1 shares a nerve which innervates the first abdominal spiracle, although this was disproven by Vasvary (1966), who found that spiracle 1 is clearly innervated by n. ab. 1, whereas dvmII1 and the second abdominal spiracle are innervated by n. ab. 2. In terms of musculature, metathoracic muscle IIIvlm2 is a reliable indicator of segmental identity, as in most insects, it inserts on sternal antecosta 2 , which marks the posterior boundary of sternum 

insertion of this muscle on the anterior margin of the chitinous $\mathrm{V}$ suggests that it is indeed the proximal portion of sternum 2 (stn2a), providing further support for our interpetations.

641 We should note that the (largely ignored) studies of Snodgrass (1933) and Kramer (1950) on 642 the musculoskeletal system, and Wohlers \& Bacon (1980) on innervation, are congruent with 643 the conclusions drawn from this study, and with Davranoglou et al. (2019c) on Fulgoromorpha.

\section{4}

\subsection{Ultrastructure of cicadid tymbal muscles}

Abdominal muscles in insects typically contain a 6:1 actin:myosin ratio (Toselli \& Pepe, 1968; Chapman, 2013), while wing muscles are characterized by a 3:1 ratio (Nahirney et al, 2006). Interestingly, the main tymbal muscle dvmII1 in cicadas (whether synchronous or asynchronous) exhibits the 3:1 actin:myosin ratio characteristic of wing muscles and expresses wing-like myofibrillar proteins (Josephson \& Young, 1981; Nahirney et al, 2006; Iwamoto, 2017), which could be interpreted as providing support for Pringle's (1954) hypothesis that this muscle is of metathoracic origin. However, as this hypothesis is not supported by the gross musculoskeletal and neurological anatomy, we instead suggest that this wing-like ratio represents a convergent adaptation, indicating that muscle ultrastructure may exhibit substantial evolutionary plasticity when required to fulfil biomechanical demands which differ from its original function (Iwamoto, 2017).

\subsection{Systematic distribution of cicadomorphan vibroacoustic organs and evolutionary implications}

By mapping the distribution of vibroacoustic organs on the cicadomorphan phylogeny, we found that tymbal or tymbal-like organs are ubiquitous in the infraorder, and that specialised mechanisms such as the deltocephaline organ likely originate from a tymbal-like precursor (Fig. 11A). An exception to this may be the typhlocybine organ, whose sternal abdominal apodemes are unlikely to have derived from tymbals, although they may be supplemented by a tymbal-like mechanism, based on certain enlarged dorsoventral muscles (dvmII4; Fig. 10) and reports of a tymbal membrane (Shaw \& Carlson, 1979). Further support stems from the systematic position of Typhlocybinae, which are nested within "tymbaled" clades, and it is likely that their common ancestor possessed a tymbal or tymbal-like organ, which later became lost or modified, with the sternal abdominal apodemes becoming the principal vibrational mechanism.

Based on parsimony, the presence of a tymbal or tymbal-like organ in the common ancestor of Cicadomorpha is likely (Fig. 11). This finding raises the question of the evolutionary relationships between two biomechanically distinct mechanisms, the cicadomorphan tymbals and the fulgoromorphan snapping organs - specifically, did these two distinct organs evolve independently from each other, or from a shared ancestral mechanism?

To answer this question, it is necessary to reassess the similarities and differences between the two mechanisms. If our proposed dorsoventral muscle homologies are accurate (Table 2), then it is clear that the two infraorders share a similar bauplan in terms of the sets of muscles on the first two abdominal segments (Fig. 12), which reflects their likely sister-group relationship (Cryan \& Urban, 2012; Song et al., 2017; Skinner et al., 2019). However, the two infraorders have exploited the morphology of the same segment in fundamentally different ways: in Cicadomorpha the lateral portion of tergum 1 has been modified into a typically ribbed tymbal 
which contains resilin at least in cicadas (rs; Figs. 13A, 14A) (Young \& Bennet-Clark, 1995, or a depigmented deformable area with rib-like wrinkles, which is primarily operated by enlarged dorsoventral muscles (Fig. 12A). In contrast, in Fulgoromorpha, the entirety of tergite 6841 is modified into a Y-shaped lobe (lb; Figs. 12B, 13B, 14B), the arms of which are separated 685 by a resilin membrane and snap together suddenly following contraction of hypertrophied dorsal longitudinal muscles (Fig. 12B; note that the dorsoventral muscles are not enlarged) of the first abdominal segment, thereby raising the entire abdomen in a snapping motion that is biomechanically distinct from the more localised buckling mechanism of a tymbal organ (Davranoglou et al., 2019c).

Certain taxa oppose the general pattern of muscle development observed within their respective infraorder (i.e. Fulgoromorpha versus Cicadomorpha), although these exceptions are rare, and likely represent secondary modifications (Fig. 11). For example, whereas it is usually the dorsoventral muscles that are hypertrophied in the cicadomorphan tymbal organ, the ventral longitudinal muscles are hypertrophied in Typhlocybinae. Conversely, whereas it is only the dorsal longitudinal muscles that are usually hypertrophied in the fulgoromorphan snapping organ, the dorsoventral muscles are also hypertrophied in most Delphacidae (Davranoglou et al., 2019c). Furthermore, in certain Cicadomorpha, tergum 1 is medially membranous and looks superficially similar to a snapping organ Y-lobe (e.g. Fig. 7D, Ledrinae). It is unlikely to function as such, however, because the associated dorsal longitudinal musculature is of normal size, whereas the dorsoventral muscles are enlarged, as expected from a tymbal-like mechanism (Fig. 7D; Ossiannilsson, 1949). Moreover, the membrane between abdominal terga 1-2 in these Cicadomorpha does not appear to have the same functionality with the resilin membrane of Fulgoromorpha (rs; Figs. 12B; 13B; 14B), which is a key functional element of the snapping organ, accommodating wholesale pitching motion of the abdomen (Davranoglou et al., 2019c).

In terms of similarities, both Cicadomorpha and Fulgoromorpha are characterised by having abdominal sterna 1-2 subdivided into distinct subunits (st1a, stn1b, stn2a, stn2b; Fig. 12A-B). In addition, the first abdominal tergum is linked to the metathorax by a distinct ridge (rg; Figs. 12-14), and the lateral margins of terga 1-2 are linked by connectors (cn; Figs. 12-13). However, some of these characters display subtle differences, which suggests that their homology should be further investigated. In Fulgoromorpha, the incorporation of the abdomen onto the metathorax is more complete than in Cicadomorpha, as stn1a, spiracle 2, the ridge, and the proximal portion of tergum 1 are joined together into a ring-like sclerite which is entirely fused to the metathorax (yellow, Fig. 13B) (Davranoglou et al., 2019c). In the Cicadomorpha that we have examined, the situation is more variable, with the distinction between the tergal and sternal components of segment 1 which are fused to the metathorax being more clear (e.g. Figs. 1-3), while spiracle 1 may be independent from the metathorax, or fused to it by means of a spine-like process (Ossiannilsson, 1949).

Although we have presented morphological similarities and differences between the 720 vibroacoustic organs of Cicadomorpha and Fulgoromorpha, it is clear from the above account that the homologies of their basic components are far from resolved. The homologies of auchenorrhynchan vibrational organs to those of their sister groups, Heteroptera and/or Coleorrhyncha, are even murkier. Heteroptera have a strongly reduced sternum 1, their abdominal sterna are much broader, and the musculature is greatly simplified; terga 1-2 are closely associated and form a simple tergal plate, which is devoid of either a buckling 
membrane or a Y-lobe (Davranoglou et al., 2017). The condition of Coleorrhyncha is poorly known (Hartung, 2007; Wessel et al., 2014), although an investigation of their morphology is currently under way (Davranoglou et al., in preparation). Although excluded from the "Tymbalia" of Wessel et al. (2014), the abdomen of Sternorrhyncha may prove particularly important in determining the origins and evolutionary transformations of euhemipteran vibrational organs, especially since certain sternorrhynchan taxa are known to generate substrate borne vibrational signals with abdominal oscillations (e.g. in Aleyrodidae, Kanmiya $\&$ Sonobe, 2002). However, the abdominal morphology of Sternorrhyncha is understudied, and the homology of their musculature to that of Euhemiptera is poorly understood (Davranoglou et al., 2019a). The study of Weber (1935) on Aleyrodes does not indicate the presence of any lobes that could represent tymbals or Y-lobes, or dorsal structures similar to tergal plates. In another group of Sternorrhyncha, the Psylloidea, substrate vibrations used by many taxa in intraspecific communication are suggested to be produced by stridulation between the axillary sclerite of the forewing and the mesothorax, stridulation between the axillary cord and anal area of the forewing or, in some cases, by tarsal oscillations (Lubanga et al., 2014; Liao et al., 2019); that is, not by abdominal structures. We conclude that it would be premature to homologise the snapping organs of Fulgoromorpha with the tymbal organs of Cicadomorpha (and the tergal plates of Heteroptera), in the sense of claiming that both represent direct modifications of a single vibrational organ present in the most recent common ancestor (MRCA) of the two groups, although we expressly do not exclude this hypothesis.

On the basis of the currently available information, it is difficult to reconstruct the evolution of auchenorrhynchan vibroacoustic organs. Based on their phylogenetic distribution, we propose two alternative hypotheses, which now await testing (Fig. 11B):

Hypothesis 1. The MRCA of Cicadomorpha and Fulgoromorpha possessed a well-developed abdominal vibrational mechanism, perhaps used for abdominal tremulation, that was modified differently in each descendant infraorder (Fig. 11). Whereas Cicadomorpha became increasingly reliant on the dorsoventral muscles of this mechanism during the evolution of their tymbal organ (Fig. 12A; with some secondary reversals), Fulgoromorpha became increasingly reliant on their dorsal longitudinal muscles during the evolution of their snapping organ (Fig. 12B).

Hypothesis 2. The MRCA of Cicadomorpha and Fulgoromorpha lacked a well-developed abdominal vibrational mechanism, and tymbals and snapping organs evolved independently (2; Fig. 11B). Given that the two infraorders are sister-groups, this is arguably a less parsimonious hypothesis. Nevertheless, parsimony does not always predict actual evolutionary pathways correctly. For example, the highly elaborated jumping mechanisms of Cicadomorpha and Fulgoromorpha are now thought to have evolved independently (Ogawa \& Yoshizawa, 2017), albeit that some limited form of jumping ability may also have been present in their MRCA.

To test between these two hypotheses, it now needs to be confirmed whether the shared similarities between the two infraorders (ridge, connector, subdivided sterna 1-2) have arisen independently or only once. This could in principle be determined by more detailed morphological studies on each of these components across Auchenorrhyncha, at different stages of development, supplemented by the use of molecular markers in evolutionary 
developmental studies. Fossil evidence from early hemipterans could also prove pivotal in resolving their origins.

\subsection{Implications for the Tymbalia hypothesis}

Tymbals were traditionally associated only with the Cicadomorpha, until Wessel et al. (2014) expanded the term to include all vibroacoustic organs of Euhemiptera [a name used for the clade Auchenorrhyncha + Coleorrhyncha + Heteroptera since Zrzavý (1990), = Tymbalia of Wessel et al. (2014); see the latter paper for a detailed discussion on nomenclature], which they suggested evolved once at the root of the clade, and were operated by a set of homologous muscles. Although our results neither confirm nor reject the Tymbalia hypothesis, they lead us to conclude that certain of the muscles important to Wessel et al.'s (2014) “tymbalian tymbal organ" were misidentified. It might be argued that the segmental identity of a few key muscles does not alter the main argument of Wessel et al. (2014), but if a demonstration of homology requires demonstration of the topographical similarity criterion of Patterson (1982), then it is not possible to test the homology of ostensibly similar structures across different taxa whilst their segmental nature remains uncertain. Furthermore, segmental identity is important in determining muscle type, which may also be crucial for inferences of homology. For example, Ossiannilsson (1949) considered muscle "Iaism" (our dvmII4; Table 2) intersegmental, as it inserted on what he interpreted as sternum 1, but originated on tergum 2 (Table 3). Our finding that sternum 1 of Ossiannilsson (1949) in fact represents stn2a would imply that the identification of this muscle as intersegmental is erroneous, and that this muscle cannot then be homologous with the true intersegmental muscles found in some Heteroptera (Davranoglou et al., 2017) and Sternorrhyncha (Weber, 1935).

Based on the above, and consistent with our previous studies (Davranoglou et al., 2019a), we recommend that use of the term "tymbal organ" be restricted to Cicadomorpha for the time being, in light both of its own biomechanical distinctness and its currently unproven homology with the vibroacoustic organs of other Euhemiptera.

\subsection{Towards a unifying terminology}

The morphology of cicadomorphan tymbal organs (especially their sternal components) is used as standard in defining the taxonomy of the infraorder, as they usually display clear speciesspecific differences (e.g. Hamilton, 1980; Le Quesne \& Payne, 1981; Ossiannilsson, 1981; Qin et al., 2014). In most cases, some of their components have been identified as belonging to the first abdominal segment, as indicated by the most commonly used terminology: sternal apodemes 1S and 2S (e.g. Ross, 1959; Catalano et al., 2012; Cao et al., 2019), male sternal apodemes 1 and 2 (e.g. Stiller, 2016), first sternal complex and second sternal complex (Catalano et al., 2011), and Ia and IIa apodemes (Ossiannilsson, 1949). Hamilton (1980, 1985) identified $\operatorname{stn} 2 \mathrm{a}$ as the second abdominal sternum, but interpreted $\operatorname{stn} 2 \mathrm{~b}$ as the third sternum. In this work, we have suggested that all of these apodemes belong to the second abdominal segment, overwhelmingly on stn2a, where they support enlarged muscles dvmII1-dvmII3, or the posteriorly enlarged apodemes on $\operatorname{stn} 2 \mathrm{~b}$, which support hypertrophied ventral longitudinal muscles.

Based on our reinterpretation of the cicadomorphan abdomen, we suggest that the aforementioned terminology should be updated as follows: sternal apodemes $1 \mathrm{~S}$ and $2 \mathrm{~S}$ become sternal apodemes $2 \mathrm{Sa}-2 \mathrm{Sb}$; male sternal apodemes 1 and 2 become male sternal 
apodemes $2 \mathrm{a}$ and $2 \mathrm{~b}$; the first sternal complex becomes the second sternal complex; and Ia apodemes becomes IIa apodemes 1 (for the apodemes of $\operatorname{stn} 2 \mathrm{a}$, as IIa apodemes is already preoccupied) and IIa apodemes 2 (for the apodemes of stn2b). Even so, we consider that the use of multiple terms to describe homologous and morphologically similar structures is unnecessary, and can be avoided by taking the following re-interpreted terms of Ossiannilsson (1949) as standard: 1) apodeme of sternum 2a (stn2a apod.): typically medially located, cupshaped muscle attachments for muscle vlmII1, which sometimes may be overtaken by dvmII12. Muscles IIIvlm2-vlmI1 also insert on their anterior surface; 2) apophysis of sternum 2a (stn2a apoph.; Fig. 10): spine-like apodeme at the edge of stn2a, its extreme apex serving as the attachment for muscles dvmII3-4; 3) apodeme of sternum $2 b$ ( $\operatorname{stn} 2 b$ apod.): mediolateral apodeme, invariably serving as the attachment for vlmII $1 ; 4)$ apophysis of sternum $2 b(\operatorname{stn} 2 b$ apoph.; Fig. 10): spine-like process, typically found in Typhlocyinae, where dvmII5-7 attach.

\subsection{Biomechanical function}

Although most major groups of Cicadomorpha have been found to communicate using vibroacoustic signals (summarised Appendix Table 1 of Wessel et al., 2014), our assumption that the tymbal and tymbal-like organs of non-cicadid Cicadomorpha utilise a cuticular buckling mechanism must be considered speculative in the majority of cases, pending behavioural studies to confirm this (but see Kuhelj et al., 2018). In any case, given the extensive morphological variation that we have observed across the Cicadomorpha, we should clearly not expect their tymbal biomechanics to be similar across the clade. This is particularly true of the tymbal organs of non-cicadid cicadomorphans: in the few cases for which their biomechanics are known, these are very different to those of the Cicadidae, even though they may share the proporty of producing tymbal-like clicks (Miles et al., 2017) or involve visible deformation of their tymbal membrane (Kuhelj et al., 2018). Moreover, even within Cicadidae, the biomechanics of the tymbal organs may vary considerably between taxa (Fonseca \& Popov, 1994). Finally, the presence of tymbals does not exclude the participation of other parts of the body in the generation of the vibroacoustic signal (e.g. tremulation of the entire abdomen, use of enlarged abdominal apodemes, participation of additional muscles, etc.).

\section{Conclusions}

In summary, we find that the segmental identity of certain key musculoskeletal components of the tymbal and other vibrational organs of Cicadomorpha may have been misidentified in previous studies, including those that have proposed evolutionary theories regarding the origins of hemipteran vibroacoustic organs (Wessel et al., 2014). Our study provides support for a previously neglected view on the debate regarding the segmental identity of the tymbal musculoskeletal system - a topic which has puzzled scientists for more than a century. This will in turn allow future studies to make progress on fundamental evolutionary questions regarding the homologies of different hemipteran vibroacoustic organs. Although we have documented the basic morphology of vibroacoustic organs across Cicadomorpha, we fully expect that other modifications of these organs remain to be documented, especially in the megadiverse Membracoidea. The characters that we have presented concerning the morphology of sclerites and muscles at the base of the abdomen have been largely neglected in previous morphological classifications and phylogenetic analyses (e.g. Davis, 1975; Dietrich \& Deitz, 1993; Zahniser \& Dietrich, 2008, 2010). Their inclusion in future studies may help to 
diagnose higher taxa within Cicadomorpha, and may assist in finding support for the phylogenetic relationships between them. These relationships still remain largely unresolved, despite the impressive amount of recently-acquired molecular phylogenomic data (Dietrich et al., 2017; Skinner et al., 2019). The biomechanics of non-cicadid tymbals and other vibrational organs are still poorly known (Kuhelj et al., 2018; Miles et al., 2017), and will undoubtedly be a fruitful subject for future studies.

\section{Author contributions}

L.-R. Davranoglou: Conceptualisation, Writing - Original draft, Writing - Review \& Editing, Methodology, Investigation, Formal analysis, Visualisation, Resources, Funding acquisition, Validation; B. Mortimer \& G. Taylor: Supervision; Writing - Review \& Editing; Funding acquisition; I. Malenovský: Investigation, Visualisation, Resources, Writing - Review \& Editing, Validation.

\section{Acknowledgements}

We are grateful to Darren Mann, Max Barclay, Mick Webb and Petr Kment for allowing us to examine the entomological collections under their care, and use the imaging facilities at their Institutions. We are indebted to Roman Rakitov, for providing specimens of M. chilensis, and to Yuri Tishechkin (together with R. Rakitov), for sharing his unpublished observations on live myerslopiids. We acknowledge the Paul Scherrer Institut, Villigen, Switzerland for provision of synchrotron radiation beamtime at the TOMCAT beamline X02DA of the SLS and thank

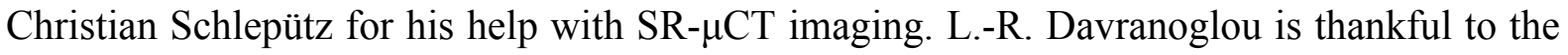
Alexander S. Onassis Public Benefit Foundation Scholarship and the Oxford-NaturalMotion Scholarhip for funding. B. Mortimer thanks the Royal Commission for the Exhibition of 1851 for research funding.

\section{References}

Cao, Y., Dmitriev, D.A., Dietrich, C.H., Zhang, Y., 2019. New taxa and new records of Erythroneurini from China (Hemiptera: Cicadellidae: Typhlocybinae). Acta Entomol. Mus. Nat. Pragae 59, 189-210.

Catalano, M.I., Brentassi, M.E., Paradell, S.L., de Remes Lenicov, A.M., 2011. First record of the genus Zygina from a Neotropical Region on Populus spp.: taxonomic and biological characteristics. J. Insect Sci. 11, 88.

Catalano, M.I., Paradell, S.L., de Remes Lenicov, A.M., 2012. First record of the genus Kybos (Auchenorrhyncha: Cicadellidae: Typhlocybinae) for Argentina. Rev. Soc. Entomol. Argent. 71, 173-176.

Chapman, R.F., 2013. The Insects: Structure and Function. 5th edition (edited by Simpson S. J. \& Douglas A.E.). Cambridge Univ. Press, Cambridge.

Cocroft, R.B., McNett, G.D., 2006. Vibratory communication in treehoppers (Hemiptera: Membracidae). In: Drosopoulos, S., Claridge, M.F. (Eds), Insect Sounds and Communication. Physiology, Behaviour, Ecology and Evolution. Taylor \& Francis, Boca Raton, pp. 305-317.

Cryan, J., 2005. Molecular phylogeny of Cicadomorpha (Insecta: Hemiptera: Cicadoidea, Cercopoidea and Membracoidea): adding evidence to the controversy. Syst. Entomol. 30, 563574. 
Cryan, J.R., Urban, J.M., 2012. Higher-level phylogeny of the insect order Hemiptera: is Auchenorrhyncha really paraphyletic? Syst. Entomol. 37, 7-21.

Davis, R.B. 1975. Classification of selected higher categories of Auchenorrhynchous Homoptera (Cicadellidae and Aetalionidae). Tech. Bull., Agric. Res. Serv., U. S. Dep. Agric. $1494,1-52$.

Davranoglou, L.R., Baňař, P., Schlepütz, C.M., Mortimer, B., Taylor, G.K., 2017. The pregenital abdomen of Enicocephalomorpha and morphological evidence for different modes of communication at the dawn of heteropteran evolution. Arthropod Struct. Dev. 46, 843-868.

Davranoglou, L.R., Cicirello, A., Mortimer, B., Taylor, G.K., 2019a. Response to "On the evolution of the tymbalian tymbal organ: Comment on "Planthopper bugs use a fast, cyclic elastic recoil mechanism for effective vibrational communication at small body size" by Davranoglou et al. 2019". Cicadina 18, 17-26.

Davranoglou, L.R., Taylor, G.K., Mortimer, B., Malenovský, I., 2019b. On the morphology and possible function of two putative vibroacoustic mechanisms in derbid planthoppers (Hemiptera: Fulgoromorpha: Derbidae). Arthropod Struct. Dev. 52, 100880.

Davranoglou, L.R., Cicirello, A., Taylor, G.K., Mortimer, B., 2019c. Planthopper bugs use a fast, cyclic elastic recoil mechanism for effective vibrational communication at small body size. PLoS Biol. 17, e3000155.de Groot, M., Derlink, M., Pavlovčič, P., Prešern, J., Čokl, A., Virant-Doberlet, M, 2011. Duetting behaviour in the leafhopper Aphrodes makarovi (Hemiptera: Cicadellidae). J. Ins. Behav. 25, 419-440.

Dietrich, C.H., Allen, J.M., Lemmon, A.R., Moriarty-Lemmon, E., Takiya, D.M., Evangelista, O., Walden, K.K.O., Grady, P.G.S., Johnson, K.P., 2017. Anchored hybrid enrichment-based phylogenomics of leafhoppers and treehoppers (Hemiptera: Cicadomorpha: Membracoidea). Ins. Syst. Div. 1, 57-72.

Dietrich, C.H., Deitz, L.L., 1993. Superfamily Membracoidea (Homoptera: Auchenorrhyncha). II. Cladistic analysis and conclusions. Syst. Entomol. 18, 297-311.

El-Sonbati, S., Wilson, M., Al-Dhafer, H., 2018. Contribution to the knowledge of selected genera of the tribe Opsiini (Hemiptera: Cicadellidae: Deltocephalinae) from the Kingdom of Saudi Arabia. Acta Entomol. Mus. Nat. Pragae 58, 257-266.

Fonseca, P.J., Popov, A.V., 1994. Sound production in a cicada: the role of different structures. J. Comp. Physiol. A. 175, 349-361.

Friedrich, F., Beutel, R.G., 2008. The thorax of Zorotypus (Hexapoda, Zoraptera) and a new nomenclature for the musculature of Neoptera. Arthropod Struct. Dev. 37, 29-54.

Hamilton, K.G.A., 1980. Review of the nearctic Idiocerini, excepting those of the Sonoran subregion (Rhynchota: Homoptera: Cicadellidae). Can. Entomol. 112, 811-848.

Hamilton, K.G.A., 1985. Review of Draeculacephala Ball (Homoptera: Auchenorrhyncha: Cicadellidae). Entomol. Abh. Staatl. Mus. Tierk. Dresden. 49, 83-101.Hartung, V., 2007. Investigations of internal anatomy of Hackeriella veitchi (Hemiptera: Coleorrhyncha: Peloridiidae) pertaining to some newly discovered behavioural traits. Unpublished diploma thesis. Humboldt Universität, Berlin.

Hoch, H., Asche, M., Bräunig, P., Ehlers, S., Hill, P.M.S., Kuhelj, A., Mühlethaler, R., VirantDoberlet, M., Wessel, A., 2019. On the evolution of the tymbalian tymbal organ: Comment on "Planthopper bugs use a fast, cyclic elastic recoil mechanism for effective vibrational 
communication at small body size" by Davranoglou et al. 2019. Cicadina 18, 13-18.

Iwamoto, H., 2017. The tymbal muscle of cicada has flight muscle-type sarcomeric architecture and protein expression. Zool. Lett. 3, 15.

Josephson, R.K., Young, D., 1981. Synchronous and asynchronous muscles in cicadas. J. Exp. Biol. 91, 219-237.

Kanmiya, K., Sonobe, R., 2002. Records of two citrus pest whiteflies in Japan with special reference to their mating sounds (Homoptera: Aleyrodidae). App. Ent. Zool. 37, 487-495.

Kramer, S., 1950. Morphology and phylogeny of auchenorrhynchous hemiptera (Insecta). Ill. Biol. Monogr. 20, 1-111.

Kuhelj, A., Škorjanc, A., Vittori, M., Žnidaršič, N., Hoch, H., Wessel, A., Virant-Doberlet, M., 2018. Vibrational signal production in Aphrodes makarovi. In: Mazzoni, V. (Ed.), 2nd International Symposium on Biotremology, Abstract Book. Fondazione Mach, S. Michele all'Adige, $\mathrm{p} 24$.

Kuhelj, A., Virant-Doberlet, M., 2017. Male-male interactions and male mating success in the leafhopper Aphrodes makarovi. Ethology 123, 425-433.Le Quesne, W.J., Payne, K.R., 1981. Cicadellidae (Typhlocybinae) with a check list of the British Auchenorhyncha (Hemiptera, Homoptera). Handbooks for the Identification of British Insects, 2(c). Royal Entomological Society, London.

Liao, Y.-C., Wu, Z.-Z., Yang, M.-M., 2019. Vibrational behavior of psyllids (Hemiptera: Psylloidea): Functional morphology and mechanisms. PLoS ONE 14, e0215196.

Lubanga, U.K., Guédot, C., Percy, D.M., Steinbauer, M.J., 2014. Semiochemical and vibrational cues and signals mediating mate finding and courtship in Psylloidea (Hemiptera): A synthesis. Insects 5, 577-595.

Marshall, D.C., Moulds, M., Hill, K.B.R., Price, B.W., Wade, E.J., Owen, C.L., Goemans, G., Marathe, K., Sarkar, V., Cooley, J.R., Sanborn, A.F., Kunte, K., Villet, M.H., Simon, C., 2018. A molecular phylogeny of the cicadas (Hemiptera: Cicadidae) with a review of tribe and subfamily classification. Zootaxa 4424, 1-64.

Mazzoni, V., Gordon, S.D., Nieri, R., Krugner, R., 2017. Design of a candidate vibrational signal for mating disruption against the glassy-winged sharpshooter, Homalodisca vitripennis. Pest Manag. Sci. 73, 2328-2333.

Miles, C.I., Allison, B.E., Losinger M.J., Su, Q.T., Miles, R.N., 2017. Motor and mechanical bases of the courtship call of the male treehopper Umbonia crassicornis. J. Exp. Biol. 220, 1915-1924.

Moore, T.E., 1961. Audiospectrographic analysis of sounds of Hemiptera and Homoptera. Ann. Entomol. Soc. Am. 54, 273-291.

Moulds, M.S., 2005. An appraisal of the higher classification of cicadas (Hemiptera: Cicadoidea) with special reference to the Australian fauna. Rec. Aust. Mus. 57, 375-446.

Myers, J.G., Myers, I.H., 1928. The significance of cicada song. A problem in insect communication. Psyche 8, 40-57.

Nahirney, P.C., Forbes, J.G., Morris, D.H., Chock, S.C., Wang, K., 2006. What the buzz was all about: superfast song muscles rattle the tymbals of male periodical cicadas. FASEB J. 20, 
982 Ogawa, N., Yoshizawa, K., 2017. Morphological dissection of behavior: thoracic musculature 983 clarifies independent development of jumping mechanisms between sister groups, 984 planthoppers and leafhoppers (Insecta: Hemiptera: Auchenorrhyncha). Org. Div. Evol. 17, 985 521-530.

986 Ossiannilsson, F., 1981. The Auchenorrhyncha (Homoptera) of Fennoscandia and Denmark. 987 Part 2: The Families Cicadidae, Cercopidae, Membracidae, and Cicadellidae (excl. 988 Deltocephalinae). Fauna Entomologica Scandinavica, Volume 7, part 2. Scandinavian Science 989 Press, Klampenborg, pp. 223-593.

990 Ossiannilsson, F., 1949. Insect drummers, a study on the morphology and function of the 991 sound-producing organ of Swedish Homoptera Auchenorrhyncha. Opus. Entomol., Suppl. X.

992 Patterson, C., 1982. Morphological characters and homology. In: Joysey, K.A., Friday, A.E. 993 (Eds), Problems in Phylogenetic Reconstruction. Academic Press, London, pp. 21-74.

994 Pringle, J.W.S., 1954. A physiological analysis of cicada song. J. Exp. Biol. 31, 525-560.

995 Pringle, J.W.S., 1957. The structure and evolution of the organs of sound-production in cicadas. 996 Proc. Linn. Soc. Lond 167, 144-159.Qin, D., Lu, S., Dietrich, C.H., 2014. A key to the genera 997 of Empoascini (Hemiptera: Cicadellidae: Typhlocybinae) in China, with descriptions of two 998 new genera and two new species. Florida Entomol. 97, 1493-1510.

999 Ross, H.H., 1959. A survey of the Empoasca fabae complex (Hemiptera, Cicadellidae). Ann. 1000 Entomol. Soc. Am. 52, 304-316.

1001 Shaw, K.C., Carlson, O.V., 1979. Morphology of the tymbal organ of the Potato Leafhopper 1002 Empoasca fabae Harris (Homoptera: Cicadellidae). J. Kansas Entomol. Soc. 52, 701-711.

1003 Shaw, K.C., Vargo, A., Carlson, O.V., 1974. Sounds and associated behavior of some species 1004 of Empoasca (Homoptera: Cicadellidae). J. Kansas Entomol. Soc. 47, 284-307.

1005 Simmons, P., Young, D., 1978. The tymbal mechanism and song patterns of the bladder cicada, 1006 Cystosoma saundersii. J. Exp. Biol. 76, 27-45.

1007 Skinner, R.K., Dietrich, C.H., Walden, K.K.O., Gordon, E., Sweet, A.D., Podsiadlowski, L., 1008 Petersen, M., Simon, C., Takiya, D.M., Johnson, K.P., 2019. Phylogenomics of 1009 Auchenorrhyncha (Insecta: Hemiptera) using transcriptomes: examining controversial 1010 relationships via degeneracy coding and interrogation of gene conflict. Syst. Entomol. 44, 1101129.

1012 Smith, J.W., Georghiou, G.P., 1972. Morphology of the tymbal organ of the beet leafhopper, 1013 Circulifer tenellus. Ann. Entomol. Soc. Am. 65, 221-226.

1014 Snodgrass, R.E., 1933. Morphology of the insect abdomen. Part II. The genital ducts and the 1015 ovipositor. Smithson. Misc. Coll. 89, 1-148.

1016 Snodgrass, R.E., 1935. Principles of Insect Morphology. Cornell Univ. Press, Ithaca.Song, N., 1017 Cai, W., Li, H., 2017. Deep-level phylogeny of Cicadomorpha inferred from mitochondrial 1018 genomes sequenced by NGS. Sci. Rep. 7, 10429.

1019 Stiller, M., 2016. Bretega, a new leafhopper genus from South Africa, with 15 new species 1020 (Hemiptera: Auchenorrhyncha: Cicadellidae: Deltocephalinae: Bonaspeiini). Entomol. Am. $1021 \quad 122,333-392$. 
Strübing, H., Schwarz-Mittelstaedt, G., 1986. The vibratory membranes in genus Euscelis. In: Drosopoulos, S. (Ed.), 2nd International Congress concerning the Rhynchota fauna of Balkan and adjacent regions, Proccedings. 18 - 22 August 1986, Mikrolimni - Prespa, pp. 49-52.

Takanashi, T., Uechi, N., Tatsuta, H., 2019. Vibrations in hemipteran and coleopteran insects: behaviors and application in pest management. Appl. Entomol. Zool. 54, 21-29.

Tishechkin, D.Y., 2003. Vibrational communication in Cercopoidea and Fulgoroidea (Homoptera: Cicadina) with notes on classification of higher taxa. Rus. Entomol. J. 12, 129181.

1030 Tishechkin, D.Y., Burlak, N.A., 2013. Pure-tone vibrational signals in small Auchenorrhyncha 1031 (Homoptera). Entomol. Rev. 93, 1085-1106.

1032 Toselli, P.A., Pepe, F.A., 1968. The fine structure of the ventral intersegmental abdominal 1033 muscles of the insect Rhodnius prolixus during the molting cycle: I. Muscle structure at 1034 molting. J. Cell. Biol. 37, 445-461.

1035

1036

1037

1038

1039

1040

1041

1042

1043

1044

1045

1046

1047

1048

1049

1050

1051

1052

1053

1054

1055

1056

1057

1058

1059

1060

1061

1062
Tröger, D., Beutel, R.G. \& Pohl, H., 2019. The abdomen of a free-living female of Strepsiptera and the evolution of the birth organs. J. Morphol. 280, 739-755.

Vasvary, L.M., 1966. Musculature and nervous system of the thorax, of the sound mechanism, and of a typical pregenital abdominal segment of the male of the annual cicada, Tibicen chloromera (Walker) (Homoptera: Cicadidae). J. N. Y. Entomol. Soc. 74, 2-55.

Vogel, R., 1923. Über ein tympanales Sinnesorgan, das mutmassliche Hörorgan der Singzikaden. Zeit. Ges. Anat. 67, 190-231.

Vondráček, K., 1949. Contribution to the knowledge of the sound-producing apparatus in the males of the leafhoppers (Homoptera-Auchenorrhyncha). Acta Acad. Sci. Nat. Moravo-siles. $21,1-36$.

Weber, H., 1935. Der Bau der Imago der Aleurodinen. Ein Beitrag zur vergleichenden Morphologie des Insektenkörpers. E. Schweizerbartsche Verlagsbuchhandlung (Erwin Nägele), Stuttgart.

Weiss, H.B., 1929. The entomology of Aristotle. J. N. Y. Entomol. Soc. 37, 101-109.

Wessel, A., Mühlethaler, R., Hartung, V., Kustor, V., Gogala, M., 2014. The tymbal: evolution of a complex vibration-producing organ in the Tymbalia (Hemiptera excl. Sternorrhyncha). In: Cocroft, R.B., Gogala, M., Hill, P.S.M., Wessel, A. (Eds), Studying Vibrational Communication, Animal Signals and Communication, 3d ed. Springer, Berlin, pp. 395-444.

Wohlers, D., Bacon, J., 1980. Sexual dimorphism of motorneurons: timbal muscle innervation in male periodical cicada and homologous structures in females. Cell Tissue Res. 209, 371382.

Wohlers, D., Williams, J.L.D., Huber, F., Moore, T.E., 1979. Central projections of fibers in the auditory and tensor nerves of cicadas (Homoptera; Cicadidae). Cell Tissue Res. 203, 3551 .

Young, D., 1975. Chordotonal organs associated with the sound producing apparatus of cicadas (Insecta, Homoptera). Z. Morphol. Tiere 81, 111-135.

Young, D., Bennet-Clark, H., 1995. The role of the tymbal in cicada sound production. J. Exp. Biol. 198, 1001-1019. 
Young, D. \& Hill, K.G., 1977. Structure and function of the auditory system of the cicada Cystosoma saundersii. J. Comp. Physiol. A. 117, 23-45.

Zahniser, J.N., Dietrich, C.H., 2008. Phylogeny of the leafhopper subfamily Deltocephalinae (Insecta: Auchenorrhyncha: Cicadellidae) and related subfamilies based on morphology. Syst. Biodiv. 6, 1-24.

Zahniser, J.N., Dietrich, C.H., 2010. Phylogeny of the leafhopper subfamily Deltocephalinae (Hemiptera: Cicadellidae) based on molecular and morphological data with a revised familygroup classification. Syst. Entomol. 35, 489-511.

Zrzavý, J., 1990. Evolution of Hemiptera: an attempt at synthetic approach. In: Koteja, J. (Ed.), Proceedings of the Sixth International Symposium of Scale Insect Studies, Cracow, August 612, 1990. Agric. Univ. Press, Cracow, pp. 19-22.

\section{Figure Legends}

Fig. 1. External morphology of the tymbals of Cicada orni. A) Dorsal view of metathorax and abdominal segments 1-2, mb, membrane; tb, tymbal; t, tergum; B) Magnified dorsal view of left tymbal, white arrow indicating the membranous boundary between the main body of tergum 1 and the tymbal, lr, long tymbal rib; pm, proximal margin of tymbal; rg, ridge; pt, pit of tymbal plate; sr, short tymbal rib; tm, tymbal membrane; tc, tymbal cover; tp, tymbal plate; C) Lateral view of tymbal, white arrow indicating the membrane separating the tymbal from tergum 1, cn, connector of terga 1-2; 1t, laterotergite; stn, sternum. Please note that the tymbal cover has been removed to enable observation of the tymbal.

Fig. 2. Ventral abdominal segmentation in Cicadidae. A) Metathorax and abdominal sterna 1-3 of a male Cicada orni, the white dashed line indicating the posterior boundaries of sternum 2 (stn2); apo, apodeme; bs, basisternum, cl, coxal cleft; cn, connector of terga 1-2; cVa, chitinous-V arm; em, epimeron; es, episternum; fm, folded membrane; lt, laterotergite; sp, spiracle; stn, sternum; tb, tymbal; tc, tymbal cover; B) Same, KOH-treated specimen, showing the intact structure of chitinous $\mathrm{V}(\mathrm{cV})$, the black dashed line showing the points of fusion of the chitinous-V arms; C) Magnified view of left tymbal connector, showing how it fuses with the proximal tymbal margin (pm); D) Detailed morphology of sternum 2 and its components in a male Oligoglena flaveola, ma, muscle attachment of stn2a for dvmII1 (main tymbal muscle); st, stem of chitinous $\mathrm{V}$, ty, tympanum. Please note that the tympanum is visible only in $O$. flaveola, as it is obscured in C. orni by the flap-like extensions of sternum 2.

Fig. 3. Ventral musculoskeletal system of the tymbal organ of a male Cicada orni, sectioned just above the connector of terga 1-2. Red and blue colours demarcate components of sternum 1 , while brown and yellow indicate components of sternum 2. Muscles are shown only for the right side of the abdomen, apo, apodeme; cn, connectors of terga 1-2; cVa, chitinous-V arm; $\mathrm{dvm}$, dorsal longitudinal muscle; fm, folded membrane; fu, furca; ma, muscle attachment of stn2a for dvmII1 (main tymbal muscle); pocx, postcoxale; sp, spiracle; stn, sternum; stn1a: anterior subdivision of sternum 1; stn1b: posterior subdivision of sternum 1; ty, tympanum; vlm, ventral longitudinal muscle. Please note that $\mathrm{cn}$, although of tergal origin, is coloured for clarity as belonging to sternum 2 , due to its fusion to the latter. 
Fig. 4. Tymbal sections of various Cicadomorpha, showing the enlargement of the principal tymbal muscle dvmII1, and the modifications of its muscle attachments. A) Anterior view of the tymbal section of Cicada orni, showing the dorsal fusion of the chitinous-V arms (cVa) to the v-bar (vb), and the enormous dvmIIl originating from the tymbals (tb) via a tendon (td). Muscle fibres visible on the left tymbal are part of dvmI1, which is otherwise not shown in this image, fm, folded membrane; $t$, tergum; stn, sternum; B) Same, posterior view, showing the tympana (ty) and the ventral longitudinal muscle of sterna 2 (vlmII1) and 3 (vlmIII1); C) Anterior view of the sectioned tymbal of Centrotus cornutus (Linnaeus, 1758), showing the enlarged dvmII1 and its muscle attachments (ma), which are incompletely fused (white dashed line marking the outline of the left muscle attachment), in contrary to their cicadid homologue (the chitinous V); D) Posterior view of the sectioned tymbal of Cercopis vulnerata, showing the insertion of dvmII1 on the posterior margin of the semi-transparent tymbal cuticle; dvmII5 is also enlarged.

Fig. 5. Variation in tymbal structure in the Cercopidae. A) Phymatostetha sp., male, dorsal view, showing tymbal (tb) position, mb, membrane; $t$, tergum; B) Same, enlarged view of right tymbal, which possesses distinct ribs (white arrows, $\mathrm{rb}$ ) and a flap-like plate (pl) on which dvmII1 originates; the connector ( $\mathrm{cn}$ ) of terga 1-2 is also visible; C) Lateral view of terga 1-2 in male Ph. signifera (Walker, 1851), showing the large number of tymbal ribs and the continuity between the tymbal and tergum 1; D) Lateral view of tergum 1 in male Cercopis vulnerata under light microscopy, where the tymbal ribs are not visible; E) Same, synchrotron microtomography, volume-rendered 3D reconstruction of tergum 1, showing the tymbal ribs, which are inconspicuous in this species.

Fig. 6. Variation in the tymbals of Aphrophoridae. A) Tymbal of male Neophilaenus campestris, lateral view, showing a distinct tymbal membrane (tm), and a row of inconspicuous ribs ( $\mathrm{rb}$ ) confined in a small region of the latter, t, tergum; cn, connector of terga 1-2; B) Lateral view of tymbal of male Lepyronia coleoptrata, showing distinct ribs which cover most of its surface; C) Same, enlarged view of tymbal ribs.

Fig. 7. Tymbals in the Membracoidea. A) Lateral view of the tymbal of an unidentified male Aetalionidae, showing the presence of distinct ribs (rb); cn, connector of terga 1-2; $t$; tergum; B) Lateral view of the bilobed tymbal-like organ of a male Cicadella viridis; the outline of faint, nearly imperceptible wrinkled structures is marked by dashed lines, and their location is indicated by a black arrow, mb, membrane; C) Dorsal view of terga 1-3 of a male Proconia sp., whose tymbals consist of a tymbal membrane devoid of ribs, separated from the main body of tergum 1 by a distinct membrane (white arrow); D) Dorsal view of terga 1-2 of Ledra mutica, whose tymbals are similar to Proconia, but they are continuous with tergum 1, and the median surface of the latter is membranous.

Fig. 8. The vibrational organs of Myerslopiidae. A) Dorsal view of terga 1-3 of Pemmation bifurca, $\mathrm{t}$, tergum; tb, tymbal; mb, membrane; sp, spiracle; dashed line indicates outline of otherwise pale tymbal; arrow indicates sclerite of tergum 1; B) Lateral view of abdominal segments 1-3 in Pemmation variabile, cn, connector of terga 1-2; arrows indicate anterior (A) and posterior (P) parts of the body; C) Anterior section of abdominal segment 2 of Mapuchea chilensis, showing the tymbal musculature, dvm, dorsoventral muscle; stn2a, anterior subdivision of sternum 2; $\operatorname{stn} 2 \mathrm{~b}$, posterior subdivision of sternum 2; dashed line of one side indicates the outline of the main dorsoventral muscles; D) Illustration of posterior section of 
abdominal segments 1-2 of $M$. chilensis, showing the tymbal musculature. Roughly same scale as panel $\mathrm{C}$.

Fig. 9. External morphology of the highly modified vibrational organ of the Deltocephalinae. A) Dorsal view of terga 1-3 of Doratura stylata, ds, drop-shaped sclerite; ms, metapostnotal sclerite; $t$, tergum; white dashed line demarcates outline of ms; B) Same, lateral view of terga $1-3$, black dashed line highlighting the outline of tymbal-like sclerite (tbl), arrows indicating anterior (A) and posterior (P) parts of the body; C) Same, enlarged view of tymbal-like sclerite, with white arrows indicating the position of ribs; D) Dorsal view of terga $1-3$ of Selenocephalus sp., white asterisks indicating the insertion of dvmII1, as inferred from dissection; E) Same, illustration of the sclerites composing the deltocephaline organ, which are obscure in the light microscopy photomicrograph, gs, gamma-shaped sclerite; ia, internal apodeme of deltocephaline organ; sp, spiracle; tr, transverse sclerite of deltocephaline organ.

Fig. 10. Ventral musculoskeletal system of the typhlocybine organ, here shown in a male Eupteryx atropunctata (modified from Ossiannilsson, 1949). Red colour demarcates components of sternum 1, while brown and yellow indicate components of sternum 2 . The black arrow indicates the position of dvmII1, which is present only in females. Muscles are shown only for the right side of the abdomen, apo, apodeme; apo, apophysis; dvm, dorsoventral muscle; fu, furca; prc, process of stn2b; sa, sternal arm of stn2b; scl, sclerite of typhlocybine organ; sp, spiracle; stn, sternum; vlm, ventral longitudinal muscle.

Fig. 11. The systematic distribution of hemipteran vibroacoustic organs and hypotheses on their evolution in the Auchenorrhyncha. A) Phylogeny of Hemiptera, with an emphasis in Cicadomorpha (Epipygidae not included). The systematic distribution of different types of hemipteran vibroacoustic organs is shown using different symbols (without an inference of homology). The order of each symbol does not imply an evolutionary sequence. The question marks (?) in the root of Auchenorrhyncha and Coleorrhyncha show the ambiguity regarding their vibrational organs. The phylogeny of Membracoidea is not exhaustive, only showing the major subfamilies. A, Aphrodinae; C, Cicadellinae; D, Deltocephalinae, Ev., Evacanthinae; Eu, Eurymelinae; I, Iassinae; L, Ledrinae; M, Megophthalminae; N, Neocoelidiinae; T, Typhlocybinae; U, Ulopinae. Please note that Aphrodinae_are polyphyletic. The phylogenetic tree was based on Cryan (2005), Dietrich et al. (2017), Skinner et al. (2019) and Song et al. (2017). Please note that the systematic position of Coleorrhyncha is ambiguous, with some studies placing them as sister to Heteroptera, and others sister to Auchenorrhyncha; B) Two mutually exclusive hypotheses on the evolution of vibroacoustic organs in the Auchenorrhyncha, based on their systematic distribution on panel A: 1) Tymbals (tb) and snapping organs (so) evolved from the same abdominal vibrational organ already present in the most recent common ancestor (MRCA) of Auchenorrhyncha; 2) The MRCA of Auchenorrhyncha lacked an abdominal vibrational organ, so tymbals and snapping organs therefore represent independent developments.

Fig. 12. Schematic illustration comparing the morphology of vibroacoustic organs of generalised Cicadomorpha and Fulgoromorpha. A) Exoskeleton and musculature of a cicadomorphan tymbal organ, showing the enlargement of dorsoventral muscles, cn, connector of terga 1-2; dvm, dorsoventral muscle; mb, membrane; rg, ridge; stn1a, anterior subdivision of sternum $1 ; \operatorname{stn} 1 \mathrm{~b}$, posterior subdivision of sternum $1 ; \operatorname{stn} 2 \mathrm{a}$, anterior subdivision of sternum 2 ; $\operatorname{stn} 2 b$, posterior subdivision of sternum 2; t, tergum; tb, tymbal; vlm, ventral longitudinal 
muscle; B) Exoskeleton and musculature of a fulgoromorphan snapping organ, showing the enlargement of dorsal longitudinal muscles, rs, resilin. Note that muscle dvmII4 is not shown in Cicadomorpha. Muscles dvmII1, 3 are mentioned as II1, II3, for clarity.

Fig. 13. Lateral view comparison of the vibroacoustic organs of Cicadomorpha and Fulgoromorpha, false-coloured SR- $\mu \mathrm{CT} 3 \mathrm{D}$ volume-rendered reconstruction. A) Tymbals of Cicada orni, cn, connector of terga 1-2 (light brown); mb, membrane; rb, tymbal ribs (indicated by arrow; light brown); rg, ridge (yellow); rs, resilin; $t$, tergum (tergum 2 green); tb, tymbal; B) Snapping organ of Agalmatium bilobum (Fieber, 1877), lb, Y-lobe of snapping organ.

Fig. 14. Dorsal view comparison of the vibroacoustic organs of Cicadomorpha and Fulgoromorpha, false-coloured SR- $\mu \mathrm{CT}$ 3D volume-rendered reconstruction. A) In Cicadomorpha, the lateral lobe of tergum 1 (t1) is modified into a vibroacoustic tymbal organ, exemplified here by Cicada orni, mb, membrane; rb, tymbal ribs (indicated by arrow; light brown); rg, ridge (yellow); rs, resilin; t2, tergum 1, green); tb, tymbal; B) In Fulgoromorpha, the entirety of tergum 1 is modified into a Y-shaped lobe (lb), known as a snapping organ, exemplified here by Agalmatium bilobum (Fieber, 1877).

\section{Table Legends}

Table 1. Species list of all 79 analysed taxa, where the type of vibroacoustic organ used is indicated for each species, along with data on individual mode of preservation, observation method, and depository. For species with tymbals, we describe whether these are ribbed or not ribbed, using a question mark (?) to indicate when the presence or absence of ribs could not be verified conclusively. Literature records are drawn from Ossiannilsson (1949), Vondráček (1949), and Kuhelj et al. (2018); all other records are based on our own examination of specimens from the following despoitories: BMNH, Natural History Museum, London; DPC, Davranoglou Personal Collection; MMBC, Moravian Museum, Brno; NMPC, National Museum, Prague; OUMNH, Oxford University Museum of Natural History; PI, Paleontological Institute, Moscow. Other abbreviations: SR- $\mu \mathrm{CT}$, synchrotron radiation microcomputed tomography.

Table 2. List of the nomenclature for muscles operating the vibroacoustic organs of Cicadomorpha and Fulgoromorpha, as described by the studies of Davranoglou et al., (2019c), Evans (1940), Ossiannilsson (1949), Pringle (1957, 1954), Vasvary (1966), Vondráček (1949) and Young $(1975,1972)$, homologised with the terminology applied in the present study. No single species that we examined had all of the muscles described in the table, and muscles of doubtful homology are listed with a question mark (?). Inferences of homology and segmental identity were formulated based on our observations of the musculoskeletal system and its innervation, which were examined using SR- $\mu \mathrm{CT}$, ethanol-preserved specimens and records from the literature. En-dash (-) denotes that the character is either absent or not reported by the study in question.

Table 3. Generalised areas of point of origin and insertion of muscles operating the vibroacoustic organs of Cicadomorpha and Fulgoromorpha, including their innervation. Muscle innervation for Cicadomorpha was based primarily on the Cicadidae dissected in this work (Table 1), and with results from previous studies on the same family (Pringle, 1957, 1954; 
Vasvary, 1966; Wohlers et al., 1979). The nervous system could only be partially reconstructed in Lepyronia, Philaenus (Aphrophoridae), Cercopis (Cercopidae), and Cicadella (Cicadellidae), with innervation established only for certain dorsoventral muscles (dvmI1, dvmII1, dvmII5, when present) and the ventral muscles of segments 1-2, which were similar to the cicadid condition. Please note that muscles dvmI 2 and dvmI3 have so far been found only in the Cicadidae. En-dash (-) denotes that the character is either absent or not reported by the study in question. $\mathrm{C}$ (Cicadomorpha) and F (Fulgoromorpha) denote that the muscle or nerve in question is found in that particular infraorder.

Table 4. List of previous names for nerves supplying the muscles operating the vibroacoustic organs of Cicadomorpha, as described by the studies of Pringle (1957, 1954), Vasvary (1966), Wohlers et al. (1979), and Fulgoromorpha, as described by Davranoglou et al. (2019c), homologised with the terminology applied in the present study.

Table 1.

\begin{tabular}{cclcc}
\hline Taxon & $\begin{array}{c}\text { Type of vibroacoustic } \\
\text { organ }\end{array}$ & $\begin{array}{l}\text { Preservation } \\
\text { method }\end{array}$ & $\begin{array}{l}\text { Observation } \\
\text { method }\end{array}$ & Depository \\
\hline
\end{tabular}

Cercopoidea

Aphrophoridae

Aphrophora alni (Fallén, 1805)

tymbal (ribbed)

ethanol; dry

Microscopy;

Photomicrography

MMBC

mounted

Microscopy;

Lepyronia coleoptrata (Linnaeus, 1758) tymbal (ribbed)

ethanol; dry

mounted

Photomicrography;

DPC;

Dissection

MMBC

Neophilaenus campestris (Fallén, 1805) tymbal (ribbed) ethanol

Microscopy;

Photomicrography; DPC;

Dissection

MMBC

Microscopy;

Philaenus spumarius (Linnaeus, 1758)

tymbal (ribbed) ethanol

Photomicrography;

Dissection

DPC

Plinia marginalis (Schmidt, 1919)

tymbal (ribbed) dry mounted

Microscopy

BMNH

Poophilus adustus (Walker, 1851)

tymbal (ribbed)

dry mounted

Microscopy

BMNH

Sphodroscarta trivirgata (Amyot \&

Serville, 1843)

tymbal (ribbed) dry mounted Microscopy

BMNH

\section{Cercopidae}

Amberana elongata Distant, 1908

tymbal (ribbed) dry mounted Microscopy

BMNH

A. dimidiata (Signoret, 1860)

tymbal (ribbed)

dry mounted

Microscopy

BMNH

Cercopis vulnerata (Rossi, 1807)

tymbal (ribbed) ethanol

Microscopy;

Photomicrography;

SR- $\mu \mathrm{CT}$; dissection

DPC 
Colsa costaestriga Walker, 1857

Kanaima katzensteinii (Berg, 1879)

Korobona lineata Distant, 1909

Mahanarva bicolor (Signoret, 1862)

Phymatostetha sp. Sabah_OUMNH-

2013-056

Phymatostetha borneensis Butler, 1874

Ph. pahangana Lallemand, 1930

Ph. signifera (Walker, 1851)

Ph. stellata (Guérin-Méneville, 1844)

\section{Clastopteridae}

Clastoptera rufescens Fowler, 1898

C. semivitrea Fowler, 1898

\section{Machaerotidae}

Blastacaena rugiceps Maa, 1963

Chaetophyes compacta (Walker, 1851)

\section{Cicadoidea}

\section{$\underline{\text { Cicadidae }}$}

Cicada orni Linnaeus, 1758

Magicicada septendecim (Linnaeus, 1758)

Oligoglena flaveola (Brullé, 1832)

Pomponia sp.

Tacua speciosa (Illiger, 1800)

Tibicen plebejus (Scopoli, 1763)

\section{Tettigarctidae}

Tettigarcta crinita Distant, 1883

$\begin{array}{llll}\text { tymbal (ribbed) } & \text { dry mounted } & \text { Microscopy } & \text { BMNH } \\ \text { tymbal (ribbed) } & \text { dry mounted } & \text { Microscopy } & \text { BMNH } \\ \text { tymbal (ribbed) } & \text { dry mounted } & \text { Microscopy } & \text { BMNH } \\ \text { tymbal (ribbed) } & \text { dry mounted } & \text { Microscopy } & \text { BMNH } \\ \text { tymbal (ribbed) } & \text { ethanol } & \text { Microscopy; } & \text { OUMNH } \\ \text { tymbal (ribbed) } & \text { dry mounted } & \text { Microscopy } & \text { BMNH } \\ \text { tymbal (ribbed) } & \text { dry mounted } & \text { Microscopy } & \text { BMNH } \\ \text { tymbal (ribbed) } & \text { dry mounted } & \text { Microscopy } & \text { BMNH } \\ \text { tymbal (ribbed) } & \text { dry mounted } & \text { Microscopy } & \text { BMNH } \\ & & & \\ \text { tymbal (?) } & \text { dry mounted } & \text { Microscopy } & \text { BMNH } \\ \text { tymbal (?) } & \text { dry mounted } & \text { Microscopy } & \text { BMNH }\end{array}$

tymbal (?)

tymbal (?) dry mounted

Microscopy

dry mounted Microscopy
$\mathrm{BMNH}$

$\mathrm{BMNH}$
Dissection;

Microscopy;

Photomicrography

DPC

BMNH

Dissection;

Microscopy;

Photomicrography

DPC

Microscopy

$\mathrm{BMNH}$

tymbal (ribbed) dry mounted

Microscopy

BMNH

Dissection;

Microscopy;

Photomicrography

DPC

$\mathrm{BMNH}$

\section{Membracoidea}




\section{Aetalionidae}

Aetalion sp.

$$
\begin{array}{ccl}
\text { tymbal (ribbed) } & \text { dry mounted } & \begin{array}{l}
\text { Microscopy; } \\
\text { Photomicrography }
\end{array} \\
\text { tymbal (ribbed) } & \text { dry mounted } & \begin{array}{l}
\text { Microscopy; } \\
\text { Photomicrography }
\end{array}
\end{array}
$$

\section{Cicadellidae}

\section{Aphrodinae}

Aphrodes spp.

$\begin{array}{ll}\text { tymbal (ribbed) } & \begin{array}{l}\text { literature } \\ \text { record }\end{array}\end{array}$

Kuhelj et al.

(2018);Ossiannilsson (1949)

\section{Cicadellinae}

Acrobelus reflexus (Signoret, 1855)

Cicadella viridis (Linnaeus, 1758)

Dichrophleps symmetrica Young, 1968

Proconia sp.

Propetes compressa Walker, 1851

\section{Coelidiinae}

Docalidia bifurcata Nielson, 1979

\section{Deltocephalinae}

Doratura stylata (Boheman, 1847)

Eupelix cuspidata (Fabricius, 1775)

Macustus grisescens (Zetterstedt, 1828)

Macrosteles cristatus (Ribaut, 1927)

Opsius stactogallus Fieber, 1866 tymbal (not ribbed)

tymbal-like organ;

abdominal apodemes

tymbal (not ribbed)

tymbal (not ribbed)

tymbal (?)

tymbal (not ribbed)

glycerol

Microscopy

BMNH

deltocephaline organ with ribs

deltocephaline organ with ribs

deltocephaline organ

deltocephaline

organ

deltocephaline

organ ethanol

dry mounted

Microscopy

literature

record

Ossiannilsson (1949)

literature

record

Ossiannilsson (1949)

Microscopy;

Photomicrography MMBC

literature

record
DPC

MMBC
Ossiannilsson (1949)
BMNH

MMBC

$\mathrm{BMNH}$

$\mathrm{BMNH}$

BMNH 
Penthimia caliginosa Walker, 1870

Selenocephalus bytinskii Lindberg, 1953

Selenocephalus sp.

\section{Evacanthinae}

Evacanthus interruptus (Linnaeus, 1758)

\section{Gyponinae}

Gypona (Marganalana) signoreti Stal, 1864

\section{Idiocerinae}

Idiocerus lituratus (Fallén, 1806)

\section{Ledrinae}

Chatura nigella (Distant, 1908)

Ledra aurita (Linnaeus, 1758)

L. mutica Fabricius, 1803

Ledromorpha planirostris Donovan, 1805

Ledropsis cancroma White, 1844

L. rubromaculata Laidlaw, 1930

Thlasia corona (Linnavuori, 1972)

Tituria planata (Fabricius, 1794)

\section{Macropsinae}

Oncopsis flavicollis (Linnaeus, 1758)

\section{Megophthalminae}

deltocephaline organ with ribs

dry mounted Microscopy

BMNH

deltocephaline organ

deltocephaline

organ

ethanol

dry mounted Microscopy

BMNH

Dissection;

Microscopy;

Photomicrography

DPC

tymbal (not ribbed)

ethanol

microscopy;

photomicrography

MMBC

tymbal (not ribbed)

dry mounted Microscopy

BMNH

tymbal;

abdominal

literature

apodemes

record

Ossiannilsson (1949)

tymbal (not ribbed)

tymbal (not ribbed)

tymbal (not ribbed)

tymbal (not ribbed)

tymbal (ribbed) tymbal (not ribbed) tymbal (not ribbed) tymbal (not ribbed)

Tymbal dry mounted Microscopy

BMNH

dry mounted Microscopy

$\mathrm{BMNH}$

Microscopy;

dry mounted Photomicrography

$\mathrm{BMNH}$

dry mounted

Microscopy

BMNH

dry mounted Microscopy

$\mathrm{BMNH}$

dry mounted Microscopy

$\mathrm{BMNH}$

dry mounted Microscopy

BMNH

dry mounted Microscopy

$\mathrm{BMNH}$ literature

record 


Agallia brachyptera (Boheman, 1847)
Megophthalmus scanicus (Fallén, 1806)
Typhlocybinae

Empoasca fabae (Harris, 1841)

Eupteryx atropunctata (Goeze, 1778)

Kybos virgator (Ribaut, 1933)

Ribautiana ulmi (Linnaeus, 1758)

\section{Ulopinae}

Cephalelus brevipilus Davies, 1988

Paracephaleus hudsoni Myers, 1923

P. marginatus (Waterhouse, 1839)

\section{Melizoderidae}

Melizoderes darwini (Funkhouser, 1934)

\section{$\underline{\text { Membracidae }}$}

Centrotus cornutus (Linnaeus, 1758)

Gargara genistae (Fabricius, 1775)

Membracis tectigera Olivier, 1792

Stictocephala bisonia Kopp \& Yonke, 1977

\section{$\underline{\text { Myerslopiidae }}$}

Mapuchea chilensis (Nielson, 1966)
Myerslopia magna Evans, 1947
M. triregia Knight, 1973

literature

record

Ossiannilsson (1949)

literature

record

Ossiannilsson (1949)

literature

record

Ossiannilsson (1949)

literature

record

Ossiannilsson (1949)

literature

abdominal

record

Ossiannilsson (1949)

abdominal

literature

record

Vondracek (1949)

$\begin{array}{llll}\text { tymbal (ribbed) } & \text { dry mounted } & \text { Microscopy } & \text { BMNH } \\ \text { tymbal (ribbed) } & \text { dry mounted } & \text { Microscopy } & \text { BMNH } \\ \text { tymbal (ribbed) } & \text { dry mounted } & \text { Microscopy } & \text { BMNH }\end{array}$

dry mounted Microscopy

BMNH
Microscopy DPC

Dissection;

$\begin{array}{ll}\text { tymbal (ribbed) ethanol } & \begin{array}{l}\text { Microscopy; } \\ \text { Photomicrography }\end{array}\end{array}$

tymbal (ribbed) dry mounted Microscopy

BMNH

tymbal (ribbed) ethanol Microscopy DPC

DPC
Dissection;

Microscopy;

ethanol Photomicrography

PI

glycerol Microscopy

BMNH

glycerol Microscopy
BMNH 


$\begin{array}{lllll}\text { Pemmation bifurca (Knight, 1973) } & \begin{array}{l}\text { tymbal (not } \\ \text { ribbed) }\end{array} & \text { ethanol } & \begin{array}{l}\text { Microscopy; } \\ \text { Photomicrography }\end{array} & \text { MMBC } \\ \text { Pemmation variabile (Knight, 1973) } & \begin{array}{l}\text { tymbal (not } \\ \text { ribbed) }\end{array} & \text { ethanol } & \begin{array}{l}\text { Microscopy; } \\ \text { Photomicrography }\end{array}\end{array}$

1249 Table 2.
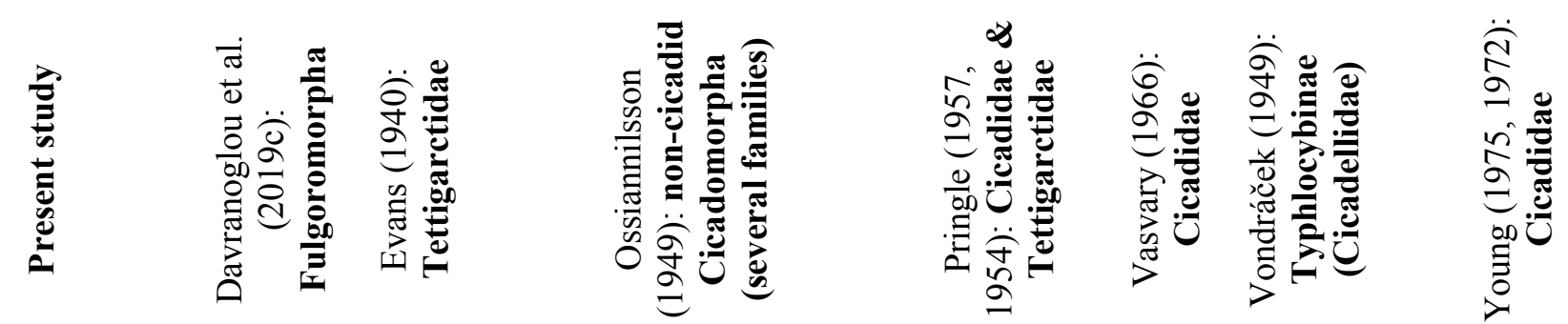

\begin{tabular}{|c|c|c|c|c|c|c|c|}
\hline dvmI1 & Idvm & - & $\begin{array}{l}\text { Iadvm3 (excluding } \\
\text { Neophilaenus) }\end{array}$ & tensor muscle & 95 & $\mathrm{ml}$ & tensor muscle \\
\hline dvmI2 & - & - & - & - & 97 & - & $\begin{array}{l}\text { accessory tensor } \\
\text { muscle }\end{array}$ \\
\hline dvmI3 & - & - & - & - & 98 & - & - \\
\hline dvmII1 & IIedvm1 & TMS & Iadvm1 & tymbal muscle & 94 & $\mathrm{p}$ & tymbal muscle \\
\hline dvmIII & Ilidvm1 & - & Iadvm2 & - & - & - & - \\
\hline dvmII3 & IIedvm2 & - & $\begin{array}{l}\text { Iadvm4 (Cicadellidae); } \\
\text { Iadvm (?)(Typhlocybinae) }\end{array}$ & $\begin{array}{l}\text { tensor tympani } \\
\text { (?) }\end{array}$ & - & pe & - \\
\hline dvmII4 & IIidvm2? & - & Iaism & - & - & - & - \\
\hline dvmII5 & - & - & IIadvm & $\begin{array}{l}\text { lat. } \mathrm{m} . \\
\text { (posterior) }\end{array}$ & 100 & - & lat.m. \\
\hline dvmII6 & IIisdvm & - & $\begin{array}{l}\text { IIaism; IIaism2 } \\
\text { (Typhlocybinae) }\end{array}$ & $\begin{array}{l}\text { lat. } \mathrm{m} . \\
\text { (anterior) }\end{array}$ & 99 & $\mathrm{qm}$ & - \\
\hline dvmII7 & - & - & IIaism1 & - & - & $\mathrm{qm}$ & - \\
\hline $\begin{array}{l}\text { IIIvlm2 } \\
\text { letathoracic) }\end{array}$ & IIIvlm2 & - & IIIvlm/IIIvlm1 & vlm [upper] & 91 & $\begin{array}{c}\mathrm{b} / \mathrm{m} \\
\mathrm{m}\end{array}$ & - \\
\hline vlmI1 & Ivlm1 & - & IIIvlm2 & vlm [lower] & - & [lower] & - \\
\hline vlmIII & IIvlm1 & - & Iavlm & $\begin{array}{l}\text { detensor } \\
\text { muscle }\end{array}$ & 93 & $\mathrm{~s} / \mathrm{o}$ & detensor muscle \\
\hline
\end{tabular}




\begin{tabular}{|c|c|c|c|c|c|}
\hline vlmII2 & - & - & - & - & - \\
\hline vlmII3 & - & - & - & - & - \\
\hline vlmIII1 & - & - & IIavlm & vent.abd.m. & - \\
\hline
\end{tabular}

Table 3.

dvmI1

dvmI2

dvmI3

dvmII1

dvmII2

dvmII3

dvmII4

dvmII5

dvmII6

C:posterior margin of tergum 1, close to spiracle 2 (behind or at level of tymbal ribs, when present); F: tergum 2 apodeme next to connector

$\mathrm{C}$ : posterior margin of tergum 1 , between spiracle 2 and insertion of dvmII1; F: tergum 2 apodeme next to connector

C: antecosta of tergum 2, above spiracle 2; F: posterior lobe of tergum 2

$\mathrm{C}$ : posterior margin of tergum 2 , close to spiracle 2 ; F : -

C, F: anterior margin (antecosta) of tergum 3

C: anterior margin (antecosta) of tergum 3, close to origin of dvmII6; F: same, but above dvmII6 posterior margin of st1a (C: on a small apodeme)

C, F: n.ab. 1

$\mathrm{C}$ : apodeme 2 of stn1a, next to chordotonal organ; F: -

C: n.ab. 1; F: -

$\mathrm{C}$ : apodeme 2 of stn1a, next to chordotonal organ; F:-

C: n.ab. 1; F: -

C: median muscle attachment of $\operatorname{stn} 2 \mathrm{a}$; F: lateral margin of $\operatorname{stn} 2 a$

C, F: n.ab. 2

$\mathrm{C}$ : anterior margin of median muscle attachment of stn2a, in front of dvmII1; $\mathrm{F}$ : median muscle attachment of $\operatorname{stn} 2 \mathrm{a}$

C:-; F: n.ab. 2

extreme lateral margin of $\operatorname{stn} 2 \mathrm{a}$

C: -; F: n.ab. 2

C, F: posterior margin of $\operatorname{stn} 2 \mathrm{a}$

C: -; F: n.ab. 2

C: muscle attachment on $\operatorname{stn} 2 \mathrm{~b}$; F: -

C: n.ab. 2; F: -

C, F: extreme lateral margin of $\operatorname{stn} 2 b$ (or its apophysis in Typhylocibinae), often on an apodeme

C, F: n.ab. 2

C: apex of $\operatorname{stn} 2 \mathrm{~b}$ apophysis; F: membrane immediately behind $\operatorname{stn} 2 \mathrm{~b}$
C, F: - 


\section{Present study}

Davranoglou et al. (2019c)

Pringle (1957, 1954)

Vasvary (1966)

Wohlers et al. (1979)

1255

n.ab. 1

n.ab. 1

Tensor

IIN7/IIN7a

tensor

n.ab. 2

n.ab. 3-9

1256 auditory nerve

IIN8-IIN8a

$$
\text { n.ab. } 2
$$

(organized into n.ab. 4-9)

abdominal nerves

IIN9

large auditory nerve 


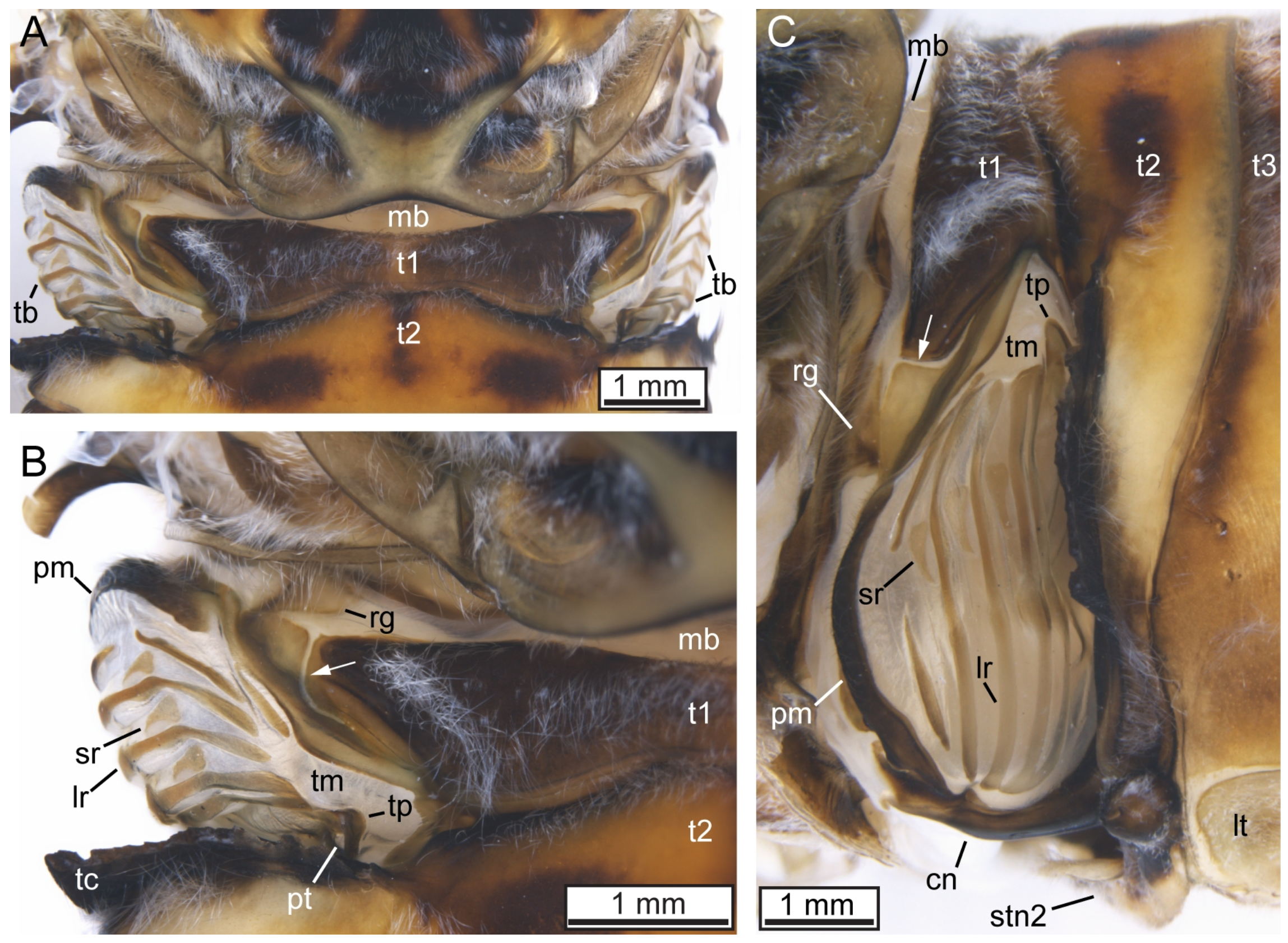




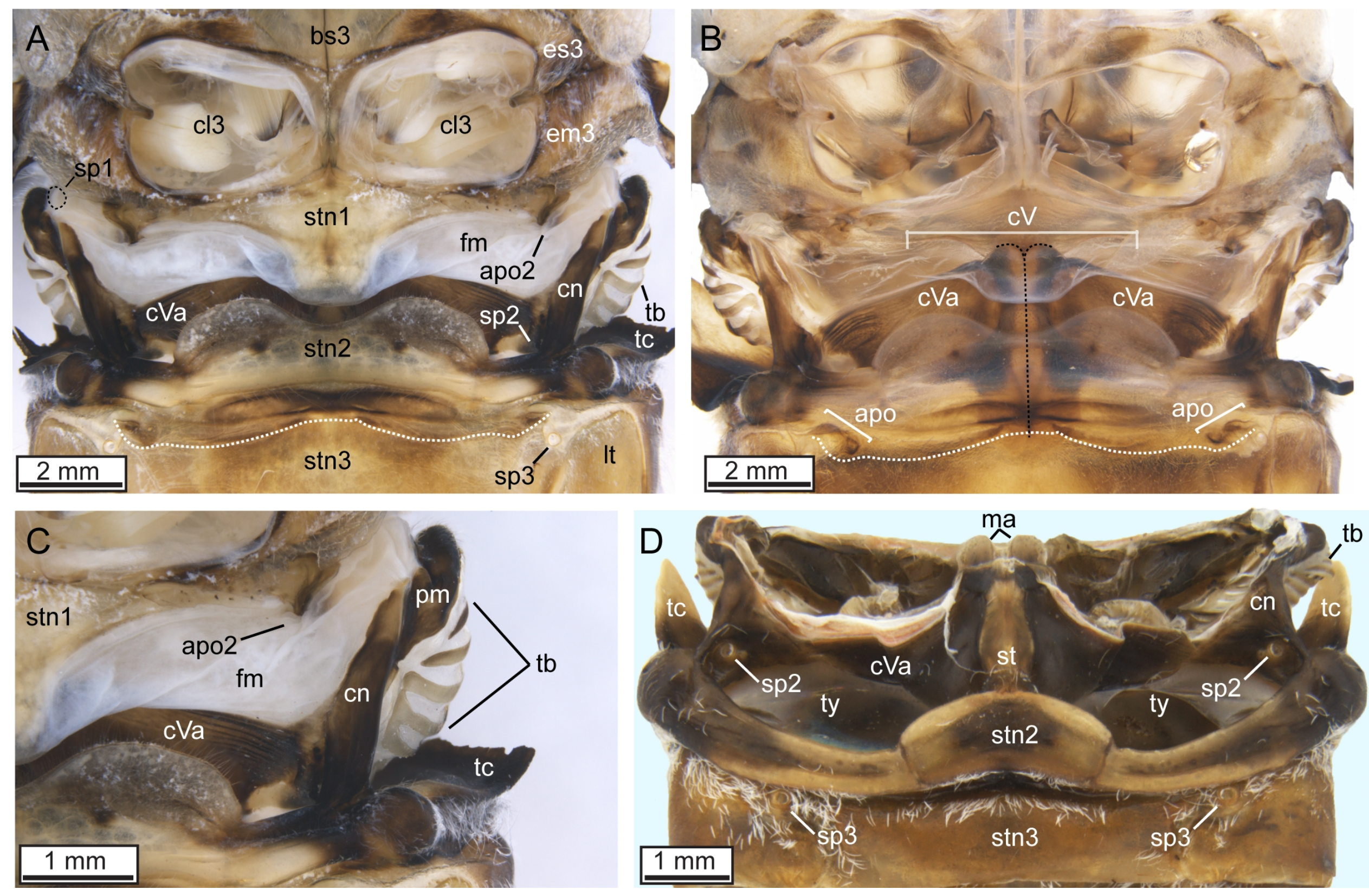




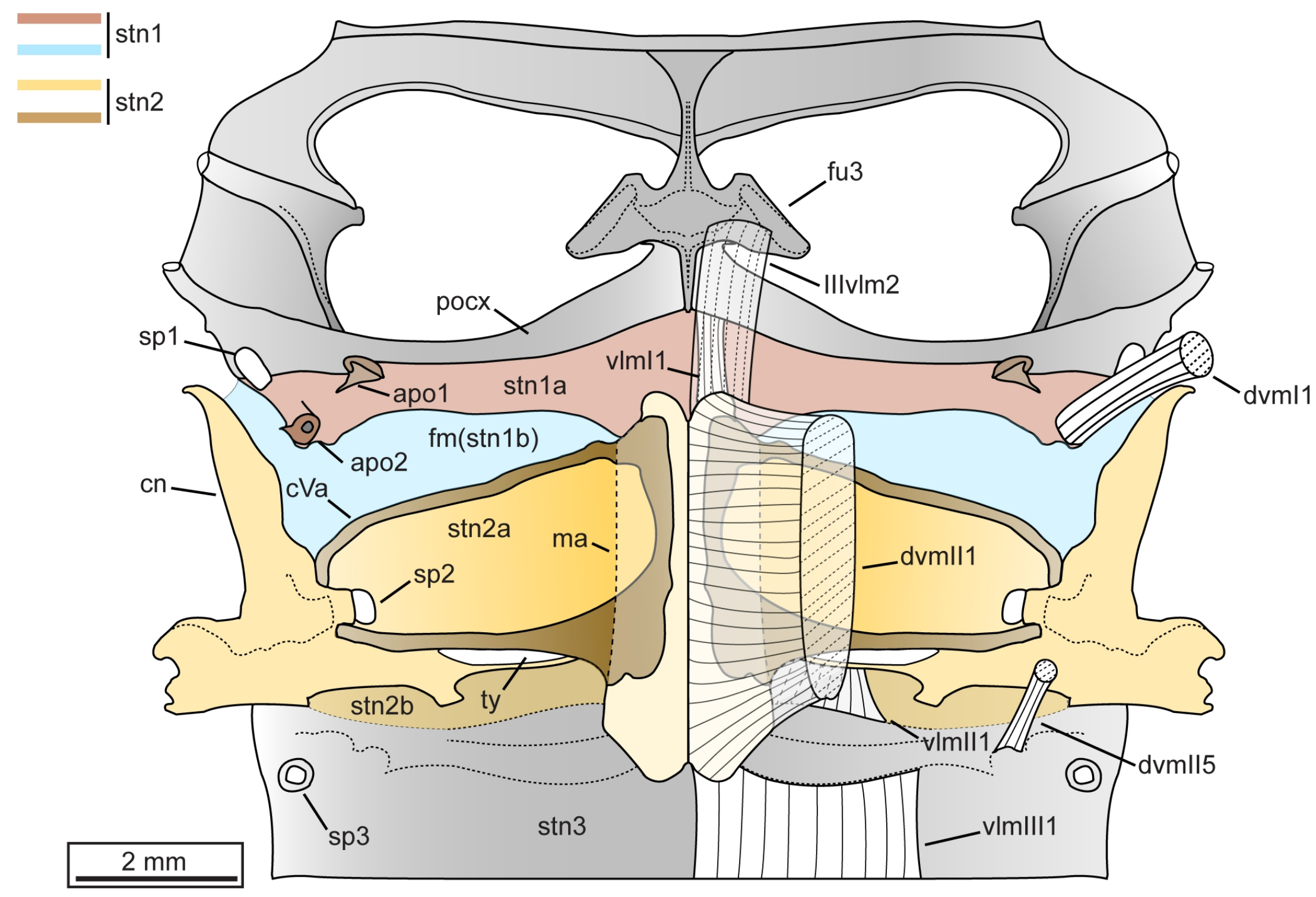




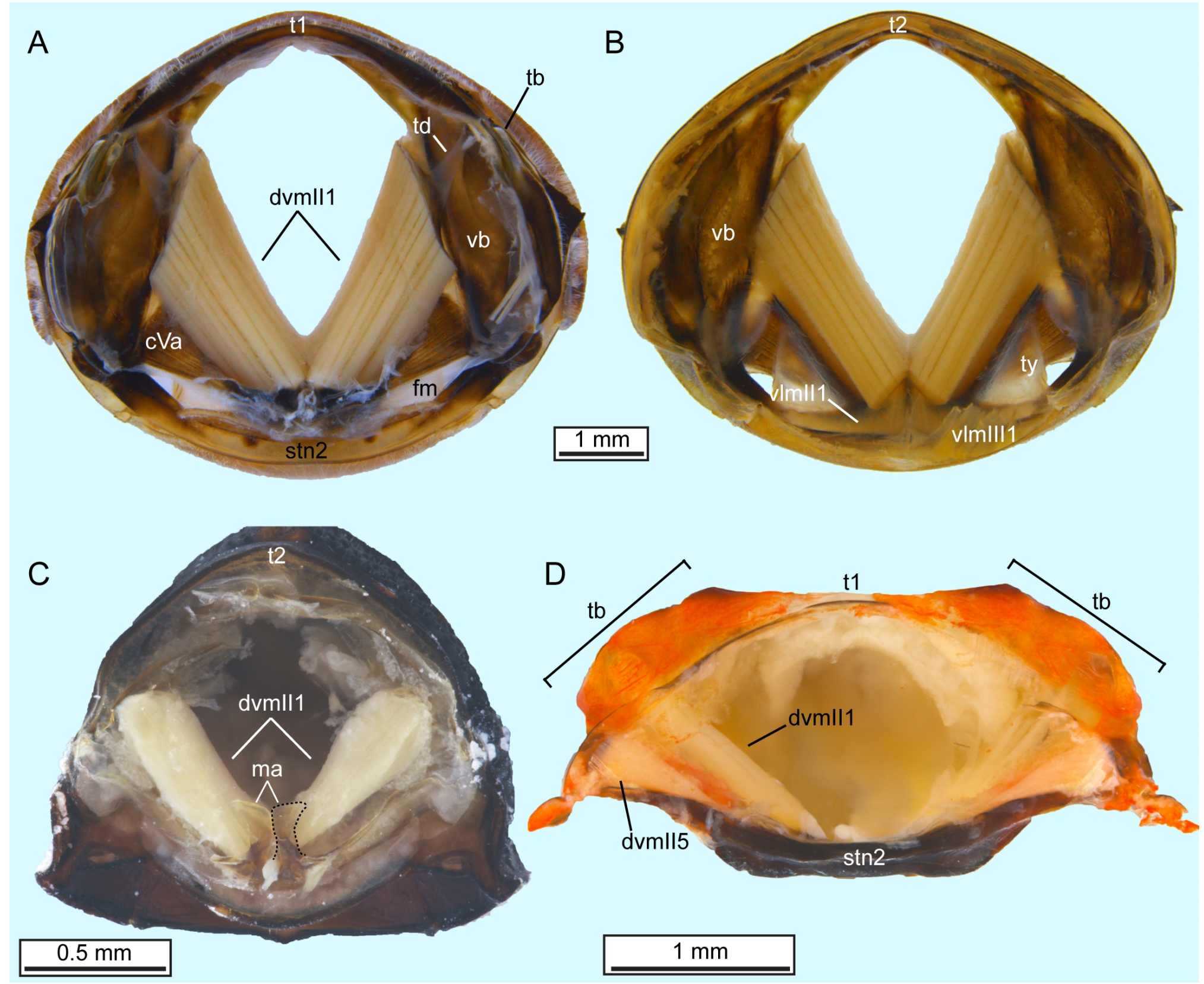



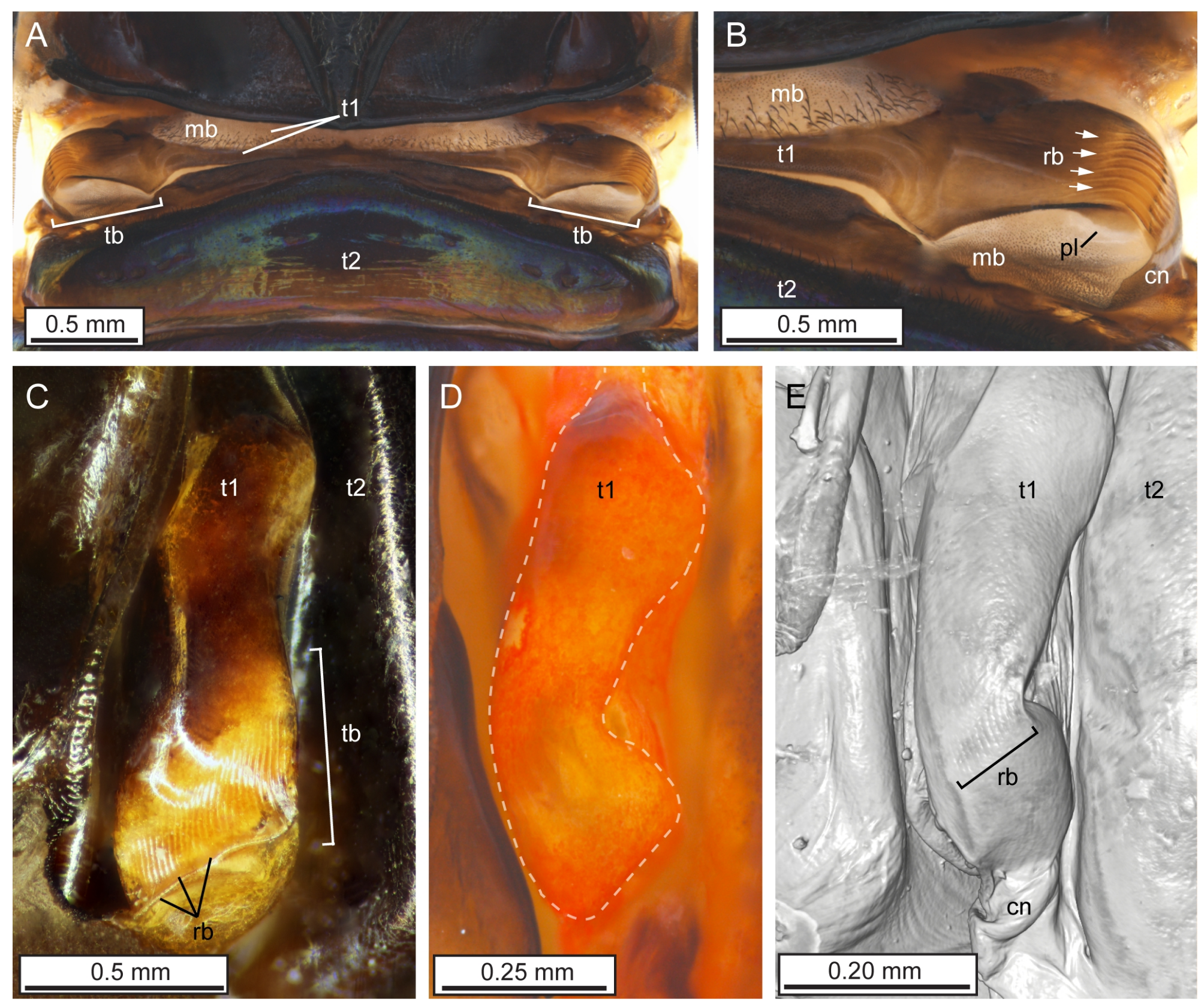

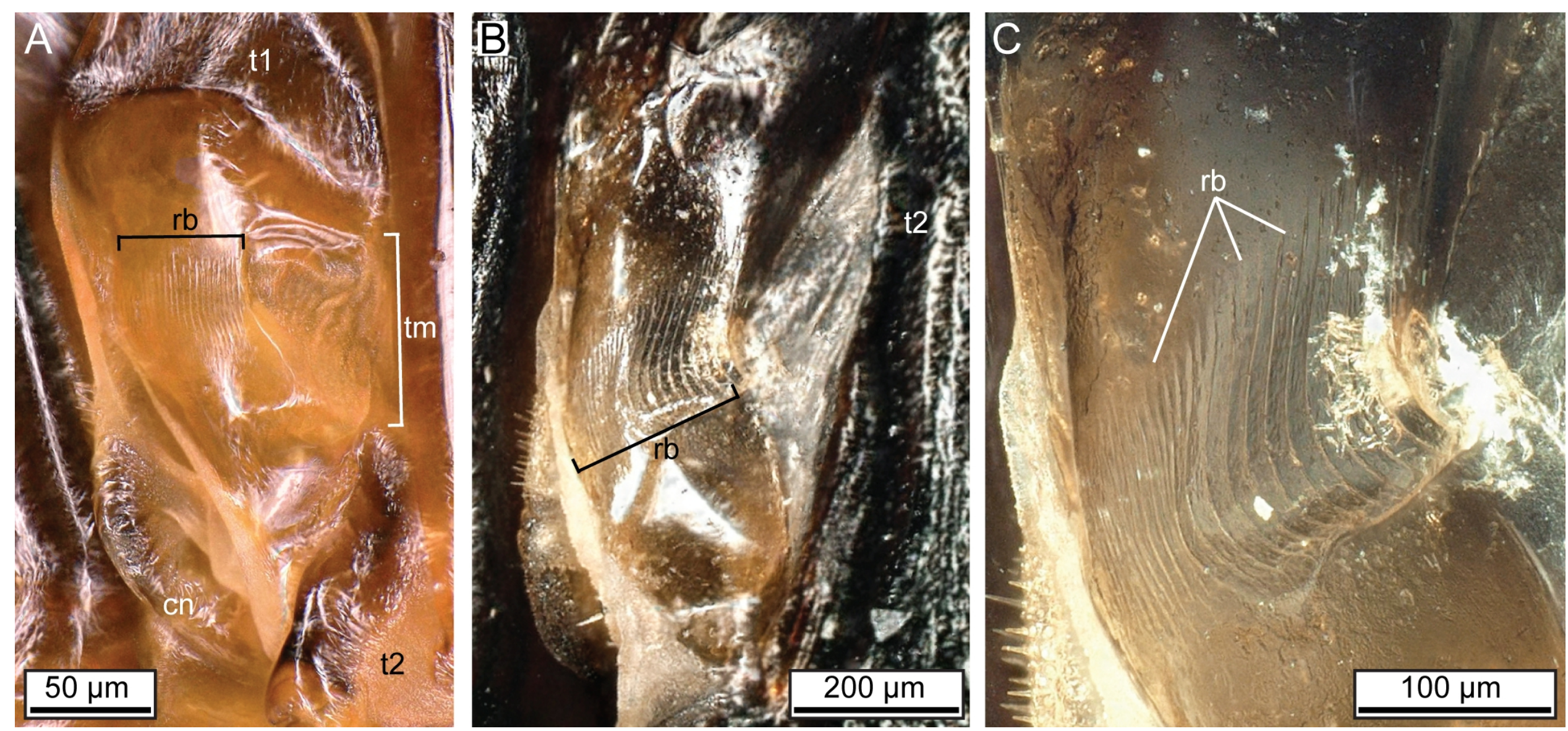

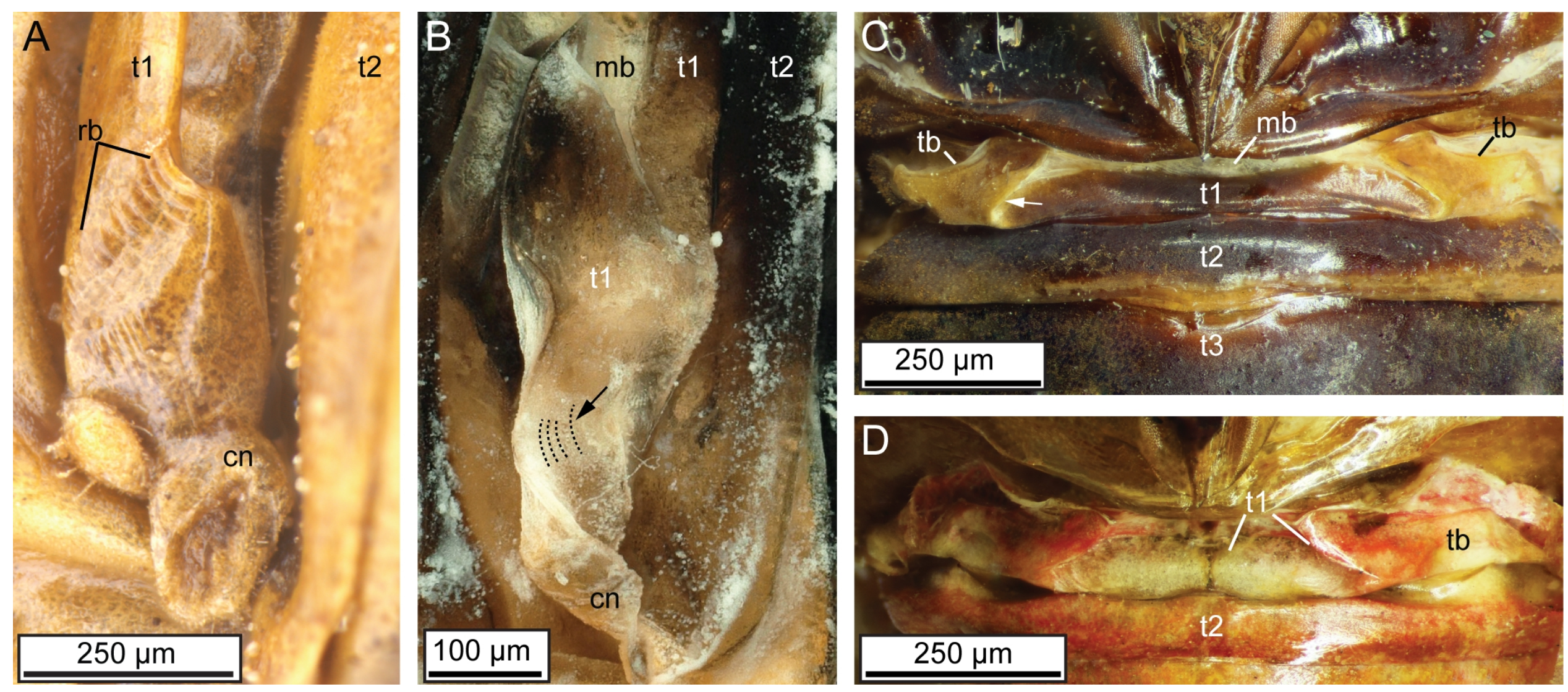

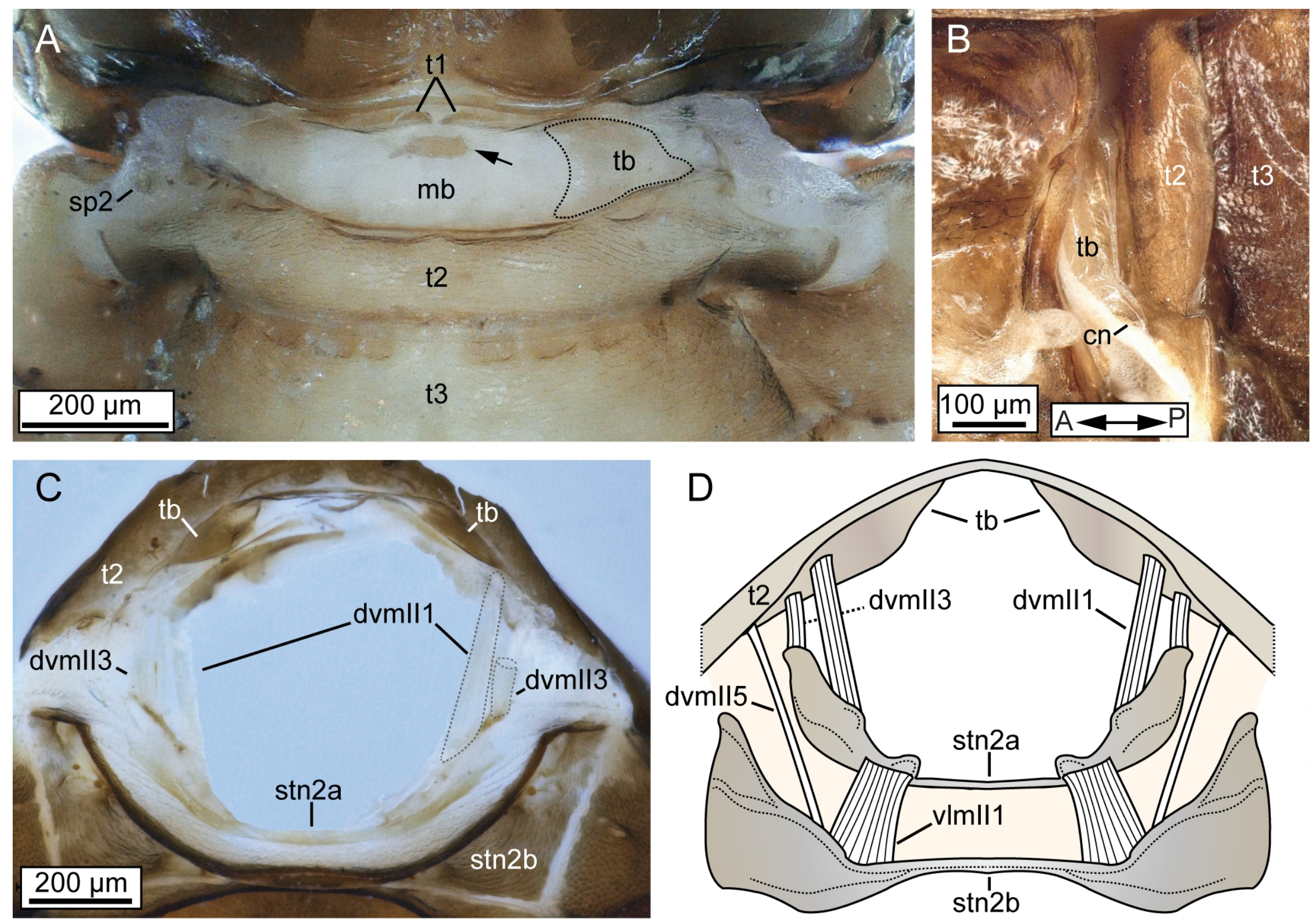

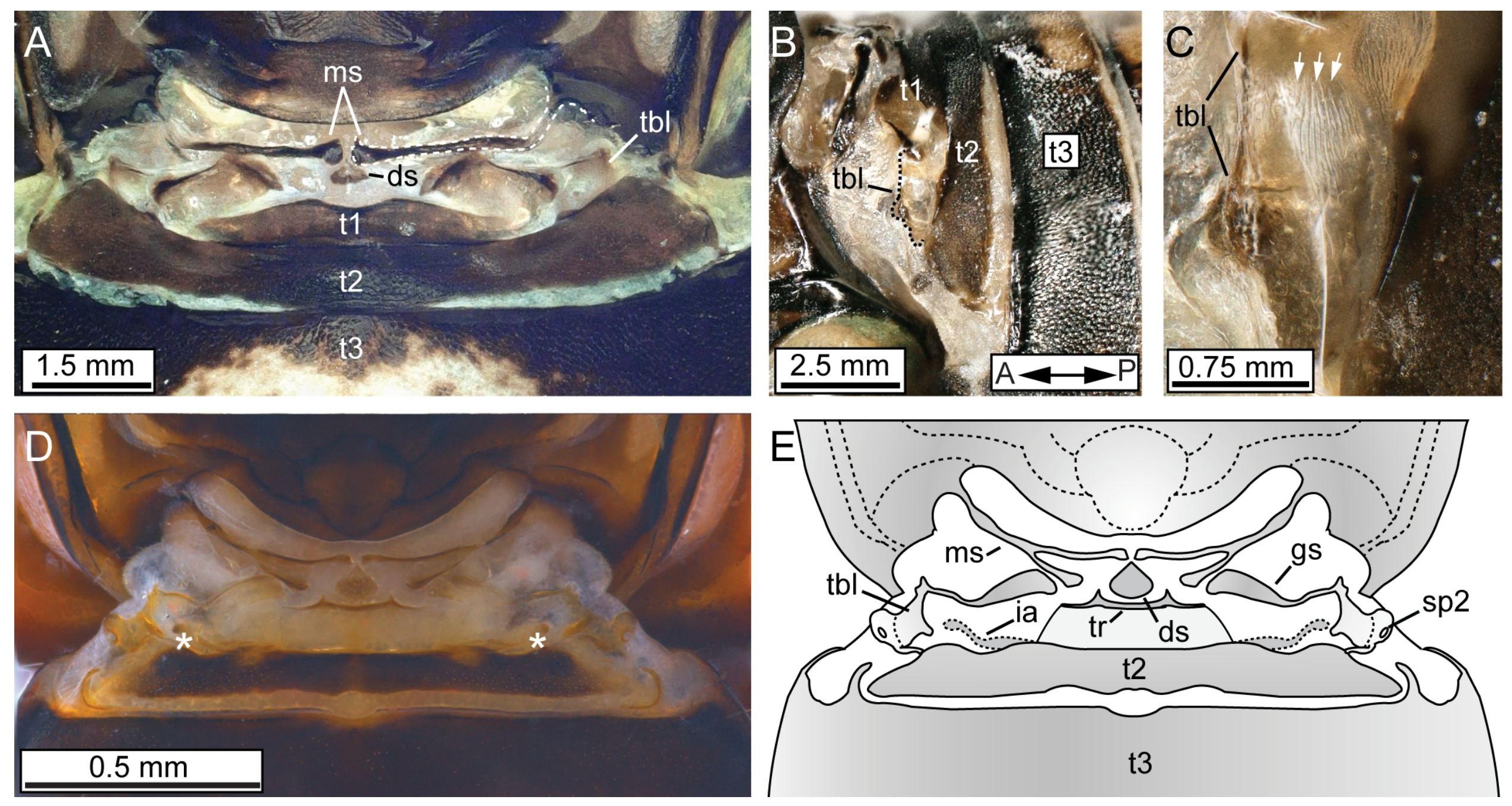


\section{I stn1}

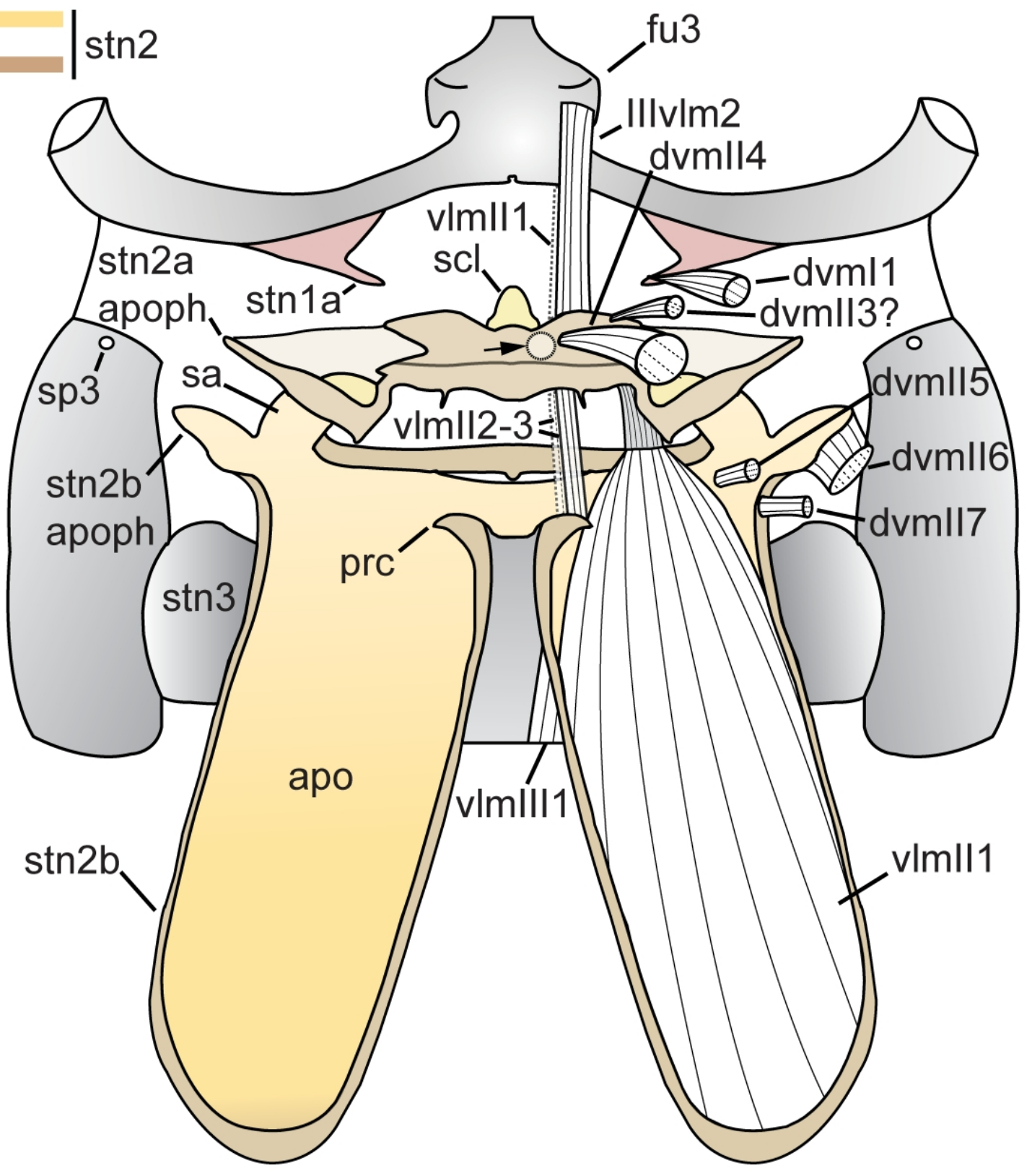




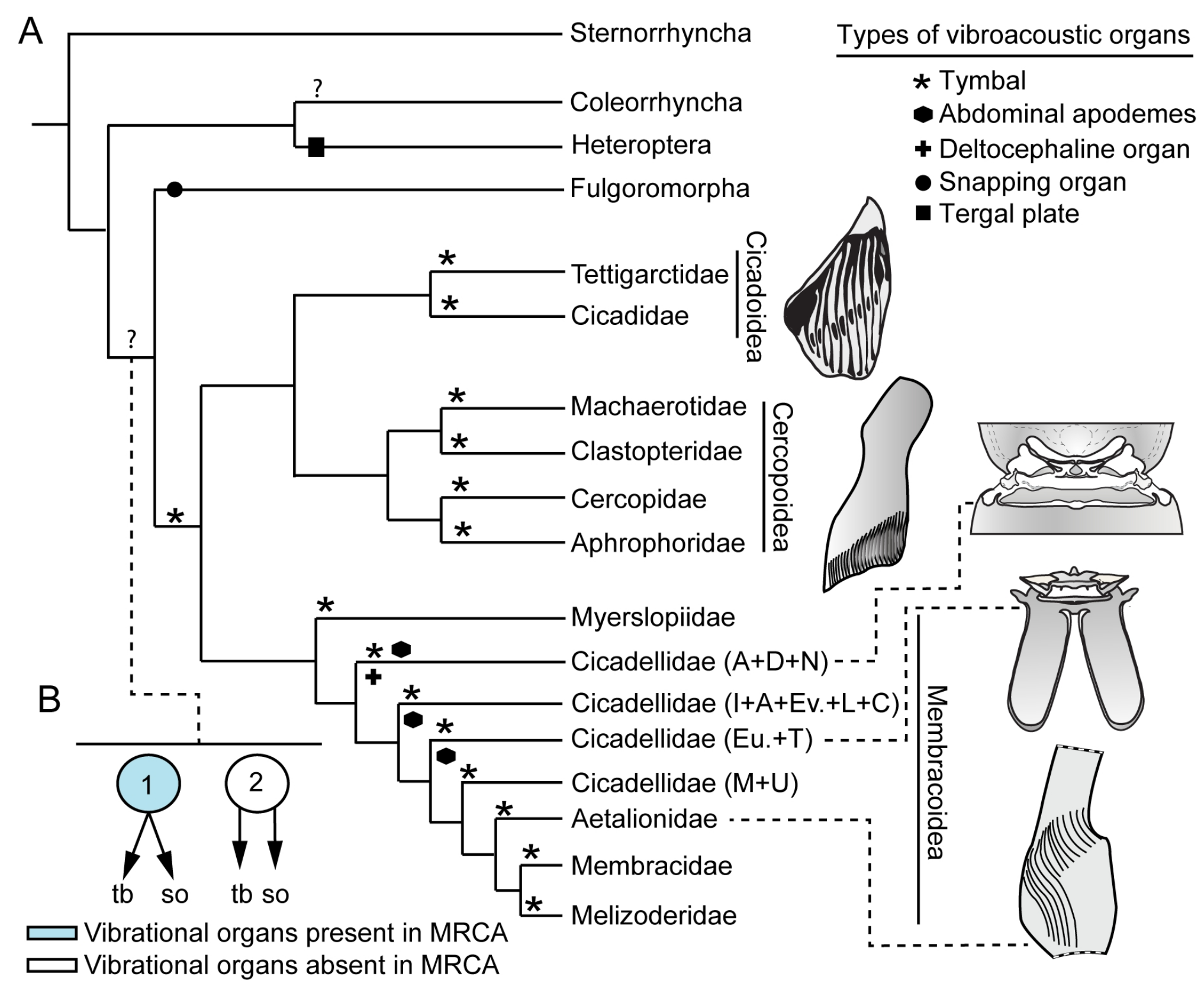


A

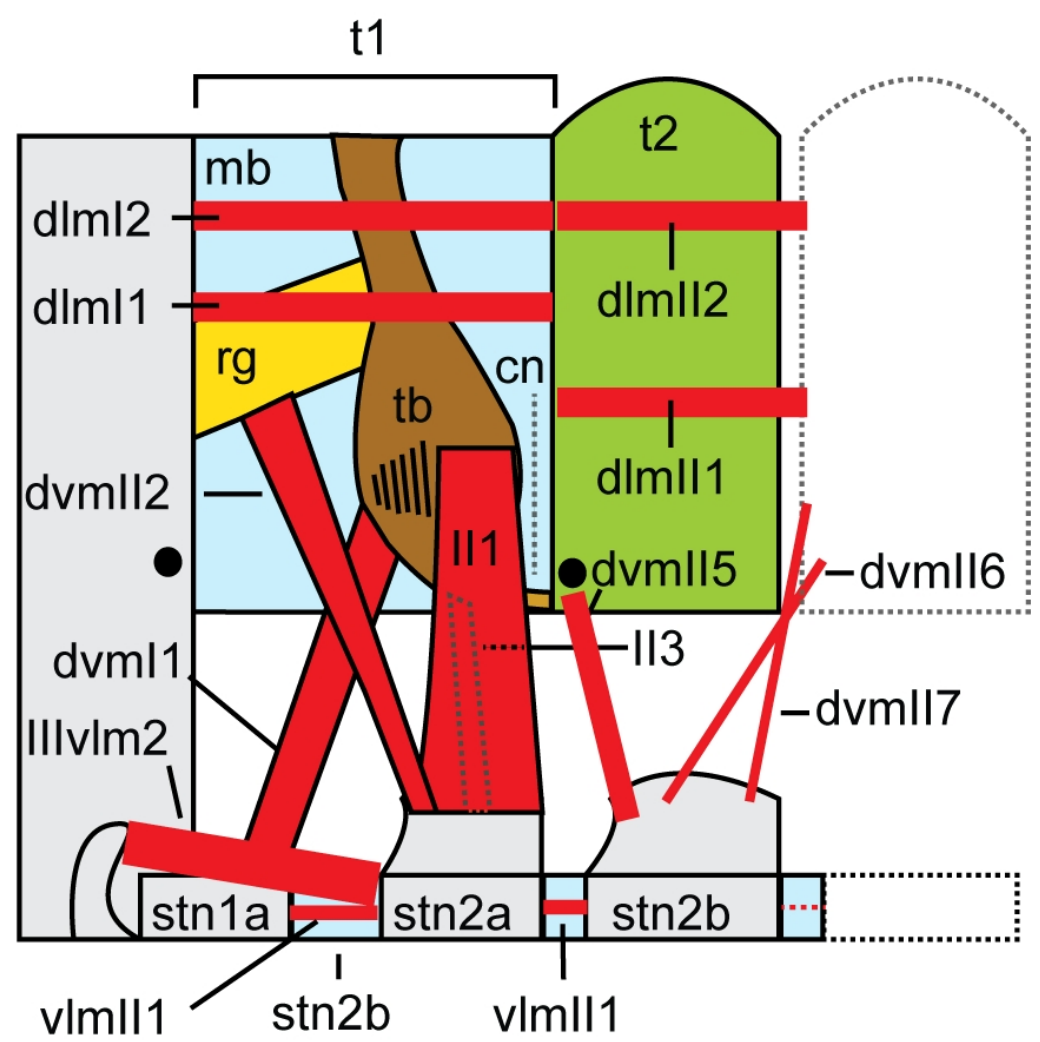

B

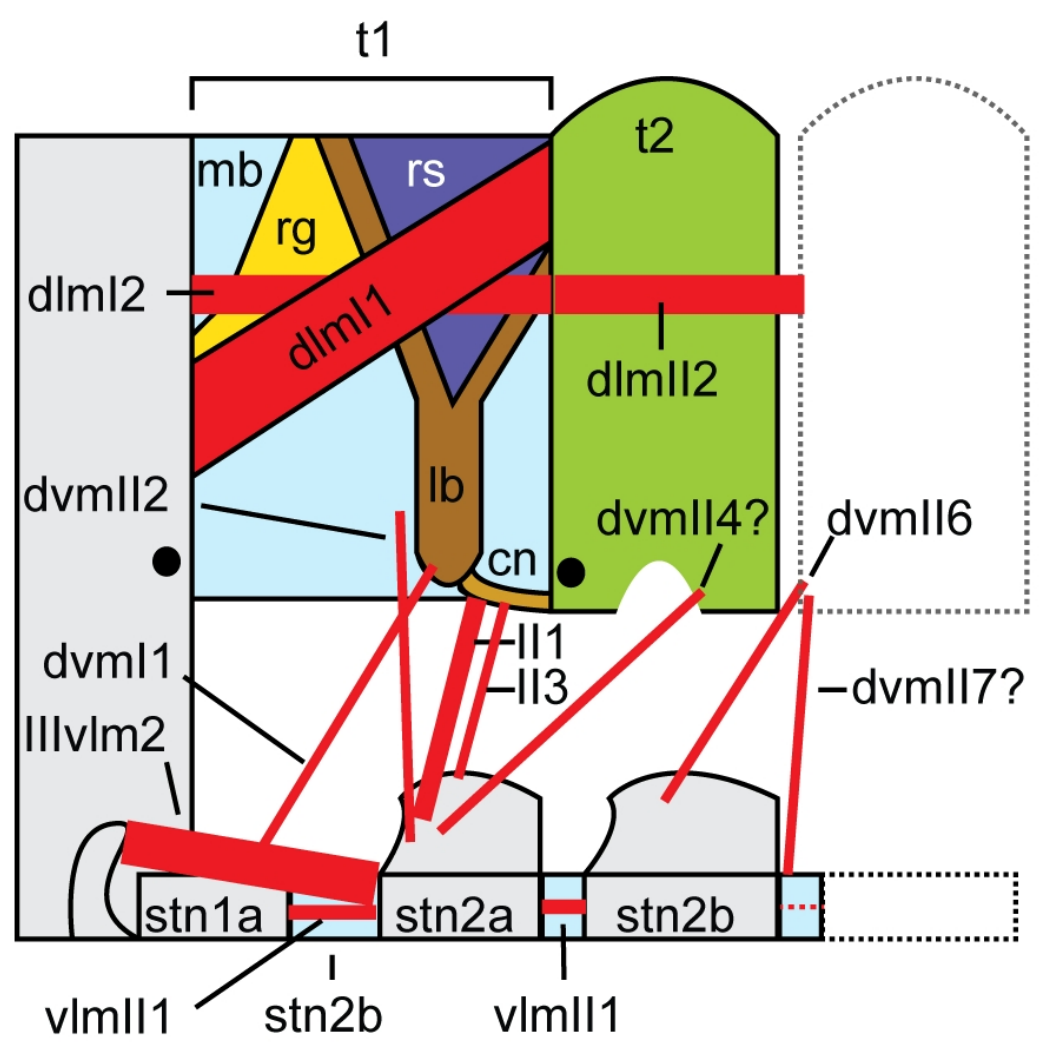




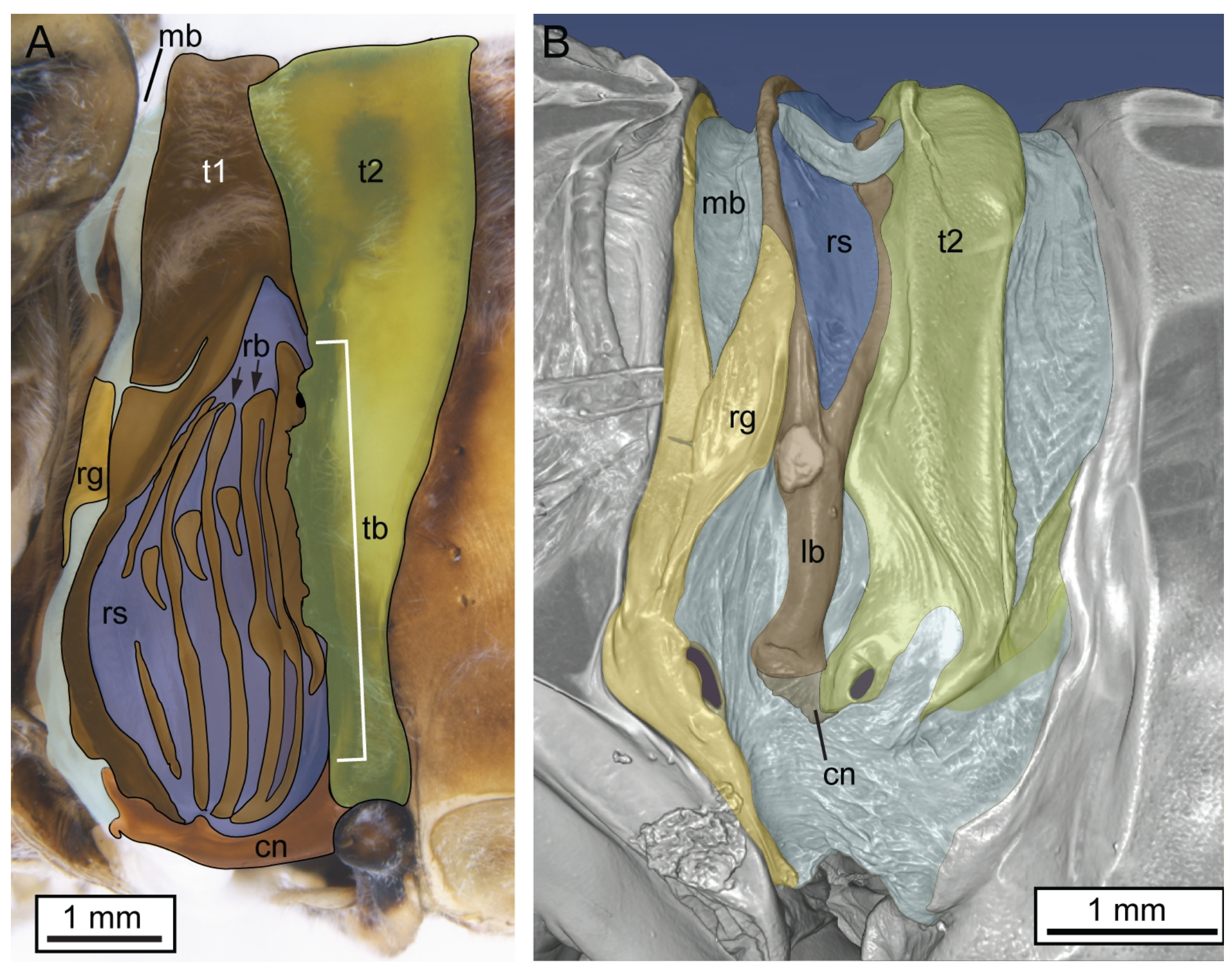




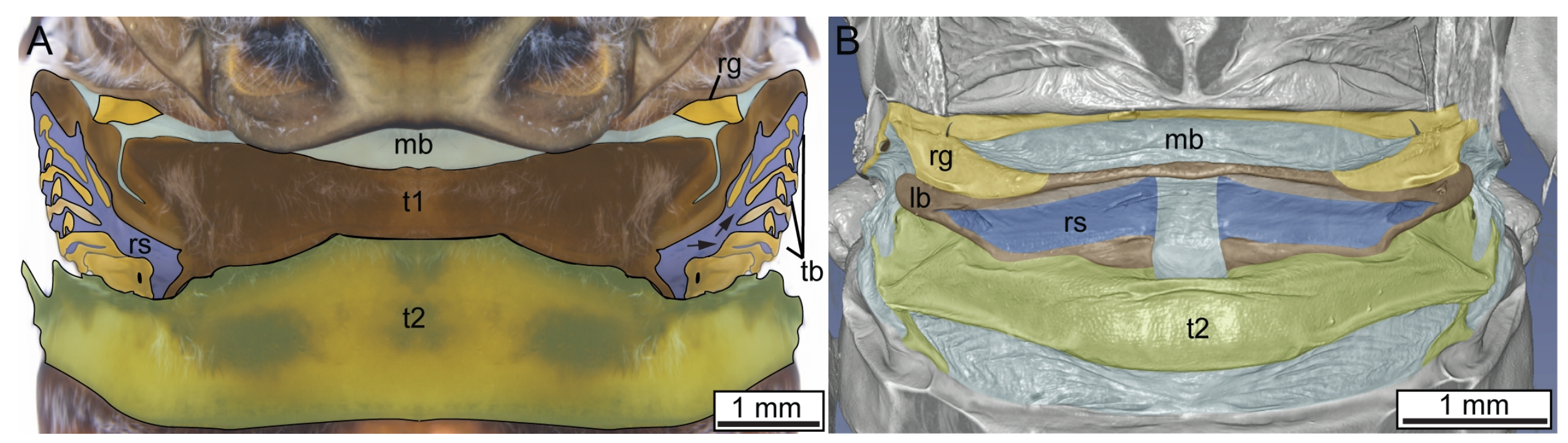




\section{Author contributions}

L.-R. Davranoglou: Conceptualisation, Writing - Original draft, Writing - Review \& Editing, Methodology, Investigation, Formal analysis, Visualisation, Resources, Funding acquisition, Validation; B. Mortimer \& G. Taylor: Supervision; Writing - Review \& Editing; Funding acquisition; I. Malenovský: Investigation, Visualisation, Resources, Writing - Review \& Editing, Validation. 